NASA/TM-2005-214036

NASA Glenn Research in Controls and Diagnostics for Intelligent Aerospace Propulsion Systems

Sanjay Garg

Glenn Research Center, Cleveland, Ohio 
Since its founding, NASA has been dedicated to the advancement of aeronautics and space science. The NASA Scientific and Technical Information (STI) Program Office plays a key part in helping NASA maintain this important role.

The NASA STI Program Office is operated by Langley Research Center, the Lead Center for NASA's scientific and technical information. The NASA STI Program Office provides access to the NASA STI Database, the largest collection of aeronautical and space science STI in the world. The Program Office is also NASA's institutional mechanism for disseminating the results of its research and development activities. These results are published by NASA in the NASA STI Report Series, which includes the following report types:

- $\quad$ TECHNICAL PUBLICATION. Reports of completed research or a major significant phase of research that present the results of NASA programs and include extensive data or theoretical analysis. Includes compilations of significant scientific and technical data and information deemed to be of continuing reference value. NASA's counterpart of peerreviewed formal professional papers but has less stringent limitations on manuscript length and extent of graphic presentations.

- TECHNICAL MEMORANDUM. Scientific and technical findings that are preliminary or of specialized interest, e.g., quick release reports, working papers, and bibliographies that contain minimal annotation. Does not contain extensive analysis.

- CONTRACTOR REPORT. Scientific and technical findings by NASA-sponsored contractors and grantees.
- CONFERENCE PUBLICATION. Collected papers from scientific and technical conferences, symposia, seminars, or other meetings sponsored or cosponsored by NASA.

- SPECIAL PUBLICATION. Scientific, technical, or historical information from NASA programs, projects, and missions, often concerned with subjects having substantial public interest.

- TECHNICAL TRANSLATION. Englishlanguage translations of foreign scientific and technical material pertinent to NASA's mission.

Specialized services that complement the STI Program Office's diverse offerings include creating custom thesauri, building customized databases, organizing and publishing research results ... even providing videos.

For more information about the NASA STI Program Office, see the following:

- Access the NASA STI Program Home Page at http://www.sti.nasa.gov

- E-mail your question via the Internet to help@sti.nasa.gov

- Fax your question to the NASA Access Help Desk at 301-621-0134

- Telephone the NASA Access Help Desk at 301-621-0390

- Write to:

NASA Access Help Desk

NASA Center for AeroSpace Information 7121 Standard Drive

Hanover, MD 21076 
NASA/TM-2005-214036

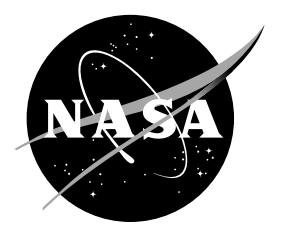

\section{NASA Glenn Research in Controls and Diagnostics for Intelligent Aerospace Propulsion Systems}

Sanjay Garg

Glenn Research Center, Cleveland, Ohio

Prepared for the

17th International Symposium on Airbreathing Engines (ISABE)

cosponsored by the German National Organizing Committee, DGLR, and MTU Aero Engines $\mathrm{GmbH}$

Munich, Germany, September 4-9, 2005

National Aeronautics and

Space Administration

Glenn Research Center 


\section{Acknowledgments}

The author will like to thank all the members of the Controls and Dynamics Branch for their enthusiasm and initiative in performing the research documented in this paper, and for providing the graphics and information for the paper. The Branch members including civil servants and on-site contractors are: Michelle Bright, Amy

Chicatelli, Dennis Culley, Jonathan DeCastro, John DeLaat, Christopher Fulton, Ten-Huei Guo, Takahisa Kobayashi, George Kopasakis, Jonathan Litt, William Maul, Kevin Melcher, Daniel Paxson, Joseph Saus, Donald Simon, Shane Sowers, and Edmond Wong. The author will also like to thank the various NASA program/project managers who have supported these research efforts.

Available from

NASA Center for Aerospace Information 7121 Standard Drive

Hanover, MD 21076
National Technical Information Service 5285 Port Royal Road Springfield, VA 22100

Available electronically at http:/ /gltrs.grc.nasa.gov 


\title{
NASA Glenn Research in Controls and Diagnostics for Intelligent Aerospace Propulsion Systems
}

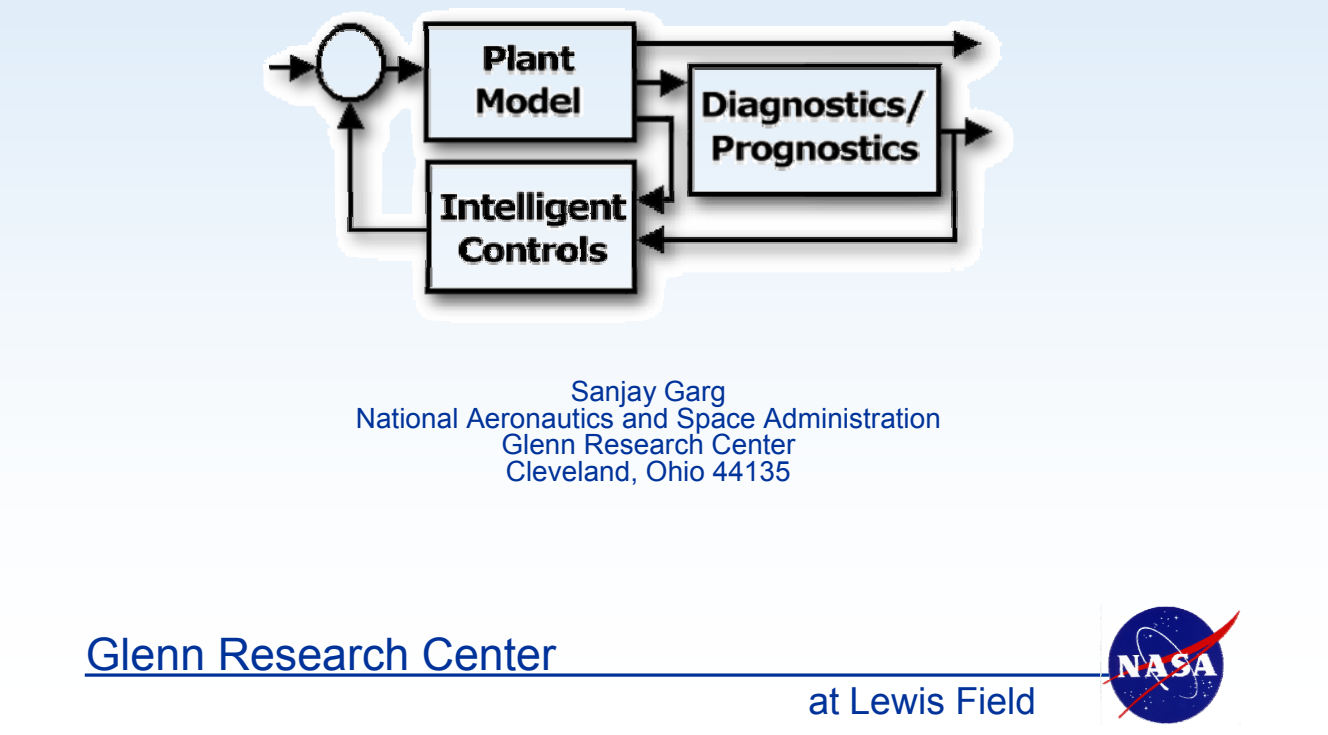

\begin{abstract}
With the increased emphasis on aircraft safety, enhanced performance and affordability, and the need to reduce the environmental impact of aircraft, there are many new challenges being faced by the designers of aircraft propulsion systems. Also the propulsion systems required to enable the NASA (National Aeronautics and Space Administration) Vision for Space Exploration in an affordable manner will need to have high reliability, safety, and autonomous operation capability. The Controls and Dynamics Branch at NASA Glenn Research Center (GRC) in Cleveland, Ohio, is leading and participating in various projects in partnership with other organizations within GRC and across NASA, the U.S. aerospace industry, and academia to develop advanced controls and health management technologies that will help meet these challenges through the concept of Intelligent Propulsion Systems. The key enabling technologies for an Intelligent Propulsion System are the increased efficiencies of components through active control, advanced diagnostics and prognostics integrated with intelligent engine control to enhance operational reliability and component life, and distributed control with smart sensors and actuators in an adaptive fault tolerant architecture. This paper describes the current activities of the Controls and Dynamics Branch in the areas of active component control and propulsion system intelligent control, and presents some recent analytical and experimental results in these areas.
\end{abstract}




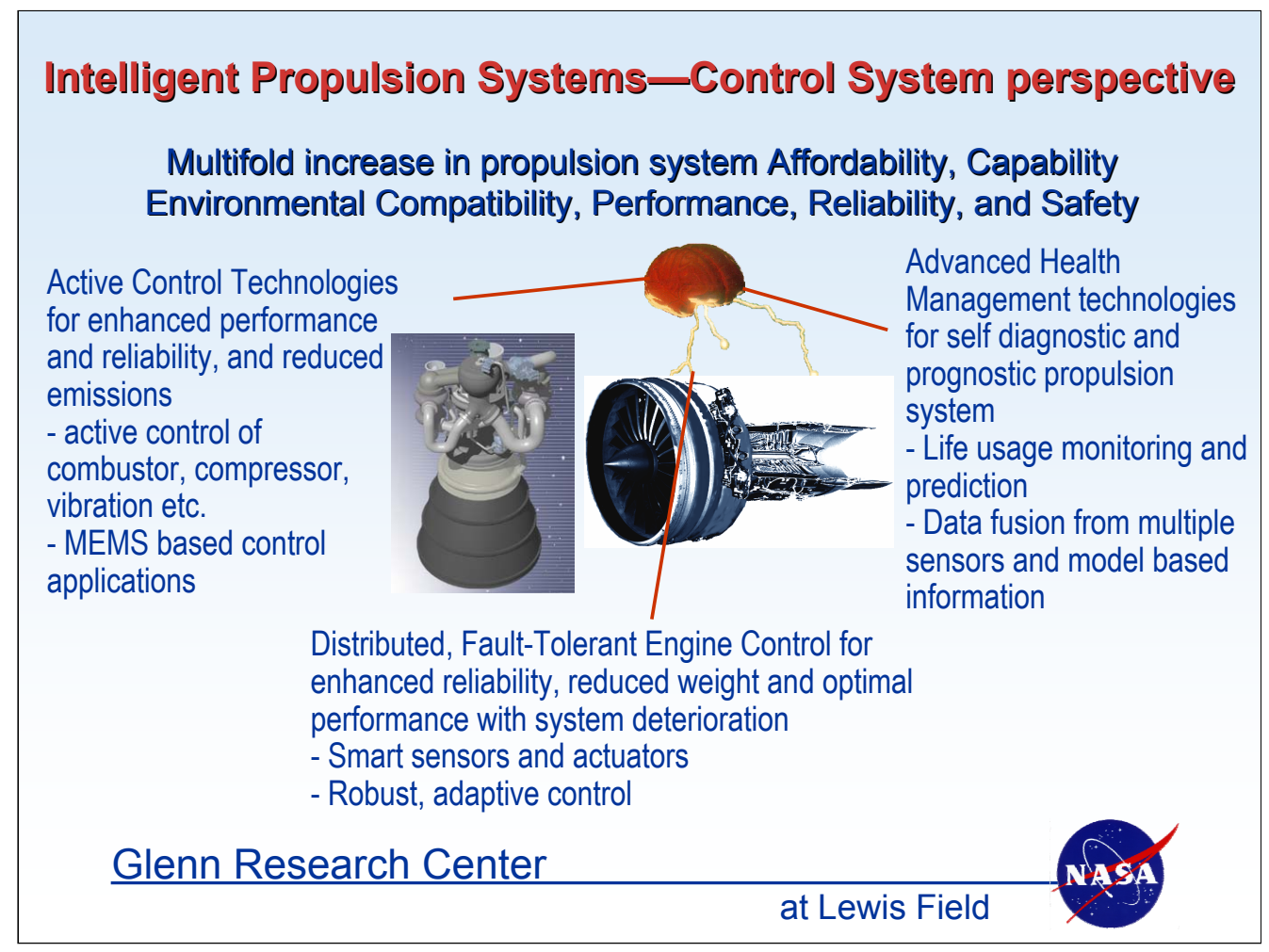

\section{Intelligent Propulsion Systems-Control System Perspective}

The control system enabling technologies for Intelligent Propulsion Systems are show above. These can be organized into three broad categories - active component control, advanced health management, and distributed fault tolerant control.

In the past engine components such as combustors, fans and compressors, inlets, nozzles etc. are designed for optimum component performance within some overall system constraints and the control design problem has been to transition the operating point of the engine from one set point to another in a most expedient manner without compromising safety. With the advancements in information technologies, the component designers are beginning to realize the potential of including active control into their component designs to help them meet more stringent design requirements and the need for affordable and environment friendly propulsion systems.

The need to have more reliable and safe engine service, to quickly identify the cause of current or future performance problems and take corrective action, and to reduce the operating cost requires development of advanced diagnostic and prognostic algorithms. The objective for this technology development is to maximize the "on wing" life of the engine and to move from a schedule based maintenance system to a condition based system.

Implementation of these concepts requires advancements in the area of robust and adaptive control synthesis techniques, and development of new hardware such as smart sensors and actuators. Attention will also need to be paid to integration of the active component control and diagnostics technologies with the control of the overall engine system which will require moving from the current analog control systems to distributed control architectures.

Ref: Garg, S., "Propulsion Control and Health Management Technology Development at NASA Glenn Research Center," 2002 JANNAF Interagency Propulsion Committee Conference, Destin, FL, April 2002. 


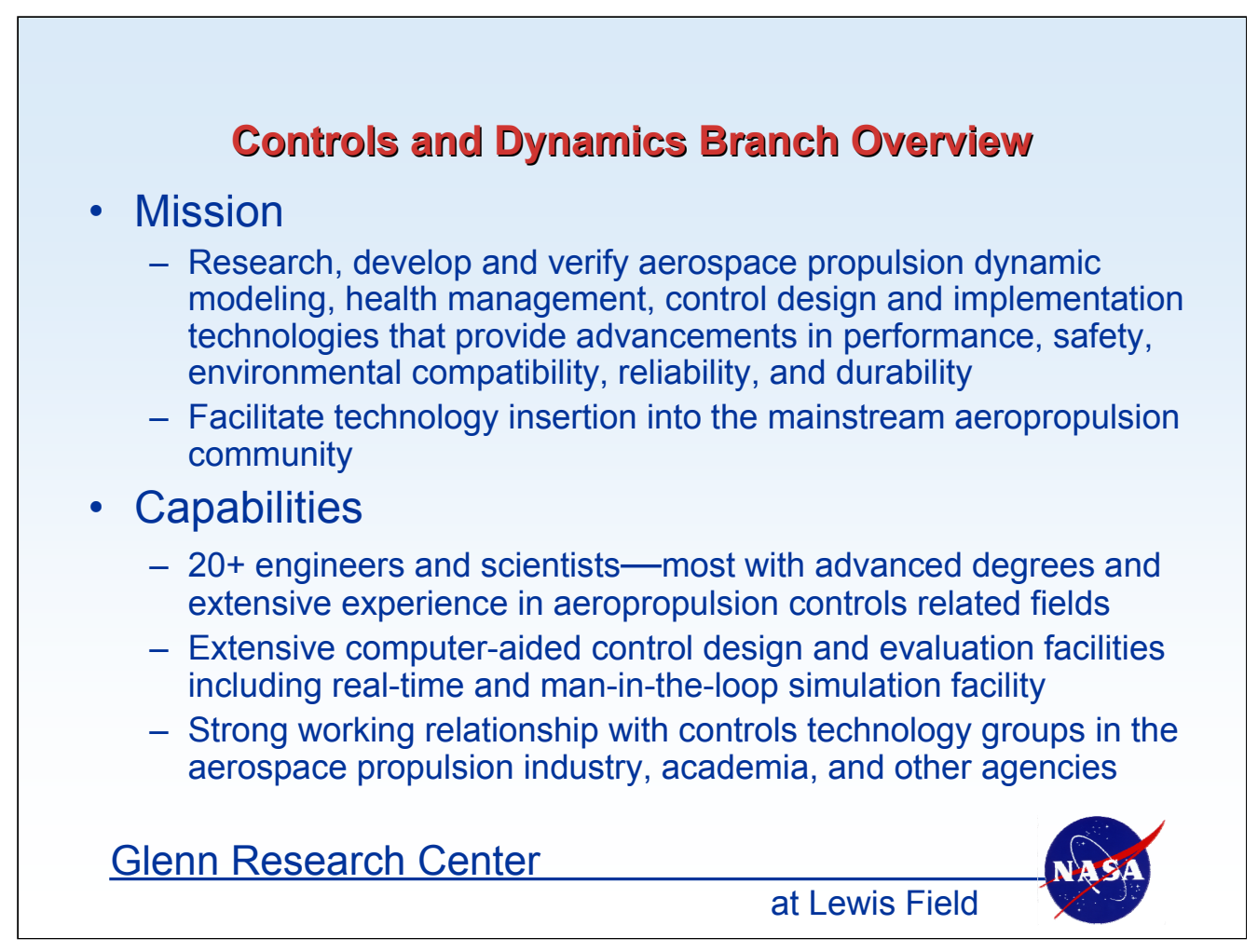

\section{CDB Overview}

The above figure is self explanatory regarding the capabilities of the Controls and Dynamics Branch (CDB). It is important to state here that this paper is not a comprehensive overview of all the propulsion controls and diagnostics related activity at NASA Glenn Research Center. It is primarily meant to focus on the major activities within the Controls and Dynamics Branch which apply to the umbrella of "Intelligent Propulsion System" technologies. 


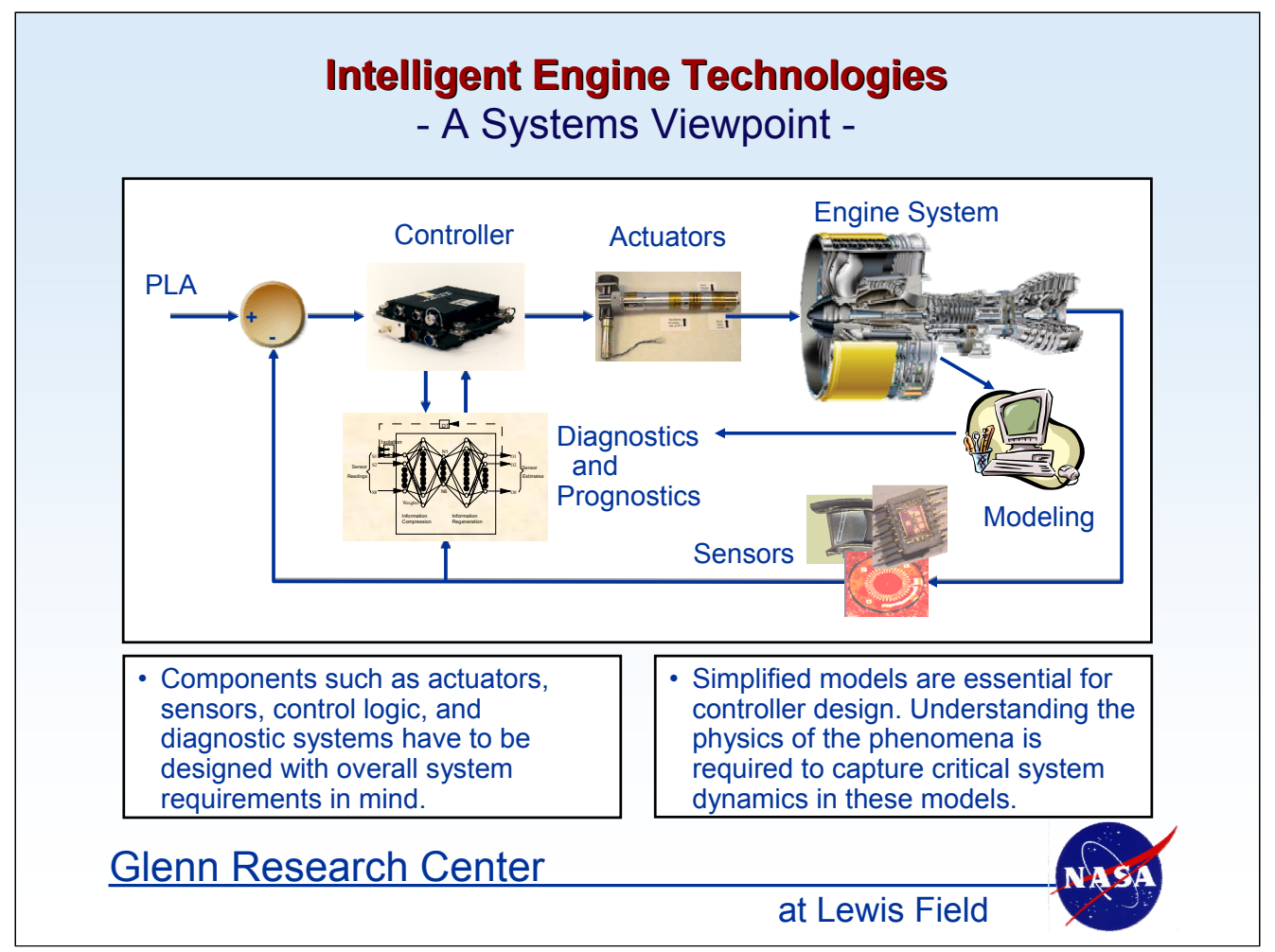

A Systems Perspective

Although a control system consists of many separate components, such as the actual control hardware and software, an actuation system, a sensing system, on-board models etc., it is important to keep an overall systems perspective in mind when designing these subcomponents.

The CDB approach to developing a controls technology for "Intelligent Propulsion System" is to start with a good overall understanding of the problem that needs to be addressed. In order to do that we interact with the technology experts in the particular areas that are relevant for that technology. For instance before starting on the task on Intelligent Control of Turbine Tip Clearance, we met with experts in the Turbine, Structures and Materials disciplines to understand what specific problem needed to be addressed, what were the potential benefits of addressing the problem, what is the state-of-the-art in terms of sensing and actuation systems available and what type of dynamic models are available and/or need to be developed for control design development and verification.

Starting with simplified computer models which simulate essential dynamics of the problem to be addressed, we then develop some preliminary specifications such as sensor requirements, actuation requirements, and closed-loop system performance requirements. Working in collaboration with our partners within GRC and industry and academia, we develop and implement an integrated task plan which develops the overall technology to the TRL (Technology Readiness Level) that is appropriate for the project that is funding the effort. 


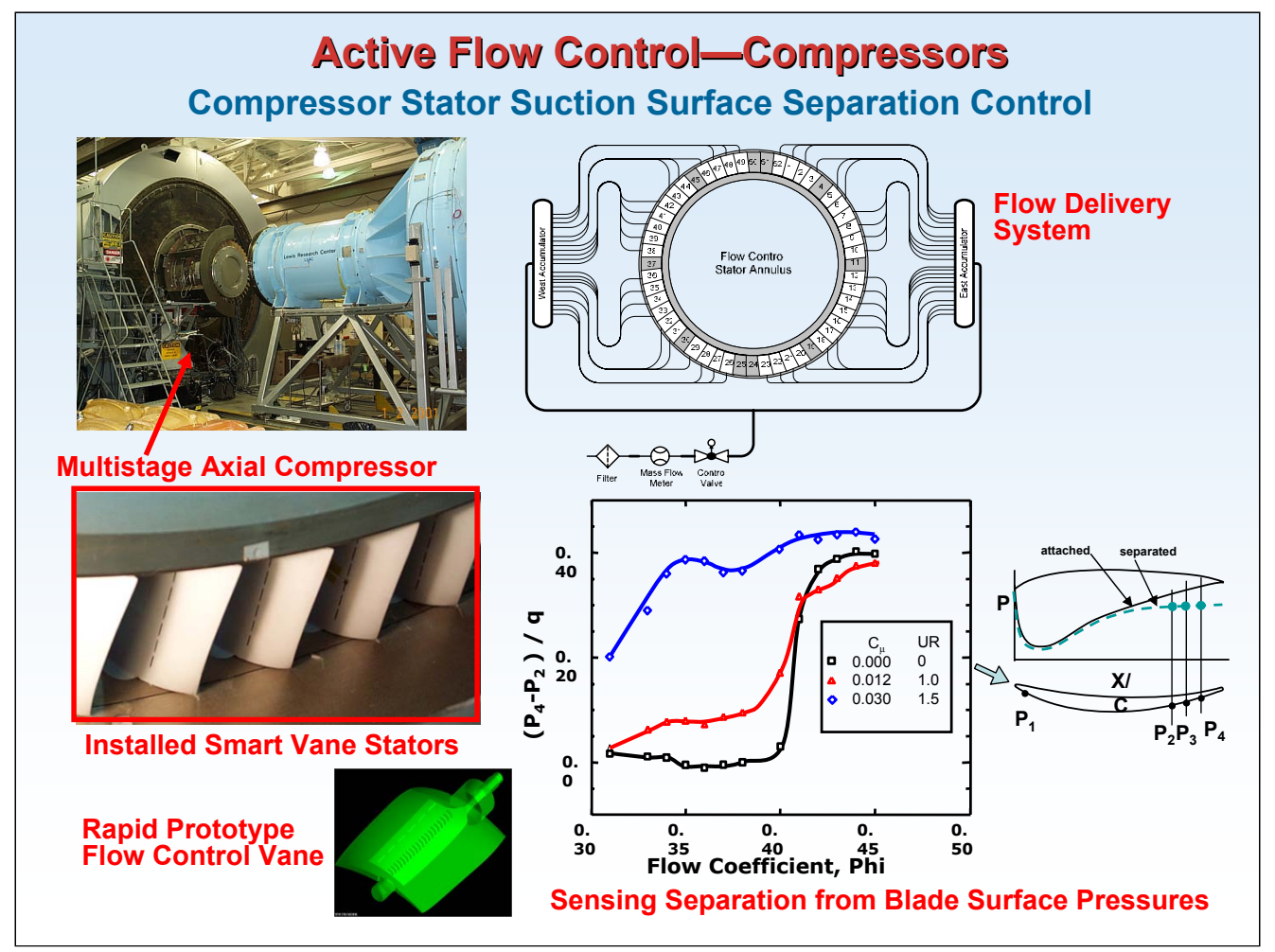

\section{Compressor Flow Control for Increased Efficiency}

One way to achieve greater compression system efficiency is to minimize the pressure loss through the stator. Typical aircraft engines have inlet guide vanes and the incidence angle for these vanes is scheduled based on the engine operating conditions. The actuation system for these guide vanes adds weight and complexity to the engine.

The objectives of the compressor flow control research at GRC is to develop and demonstrate flow control methods that utilize air injection in compressors for control of flow separation within stators. Successful separation control may enable improved performance in two ways: i) by increasing the range of incidence angles over which total pressure loss is acceptable and ii) by increasing the loading level at which an acceptable level of loss occurs. The tangible benefits may be an increase in operability and an increase in stator aerodynamic loading, which can lead to reduced engine weight and parts count through lower solidity.

The current research is focused on development of stator vane separation control methods using a low speed compressor facility. Recently, active closed-loop flow control was successfully demonstrated on a full annulus of stator vanes in the low speed axial compressor. Two independent methods of detecting separated flow conditions on the vane suction surface were developed. The first technique, shown in the figure above, detects changes in static pressure along the vane suction surface, while the second method monitors variation in the potential field of downstream rotor. In response to the detection of separated conditions, injection along the suction surface of each vane was used. A control algorithm, which provided a proportional response of the injected mass flow rate to the degree of separation, thereby minimizing the penalty on the compressor system, was developed and successfully demonstrated.

Ref: Bright, M.M, Culley, D.E., Braunscheidel, E.P., and Welch, G.E., "Closed Loop Active Flow Separation Detection and Control in a Multistage Compressor," AIAA-2005-0849 presented at the 43rd Aerospace Sciences Meeting, Reno, NV, January 2005. 


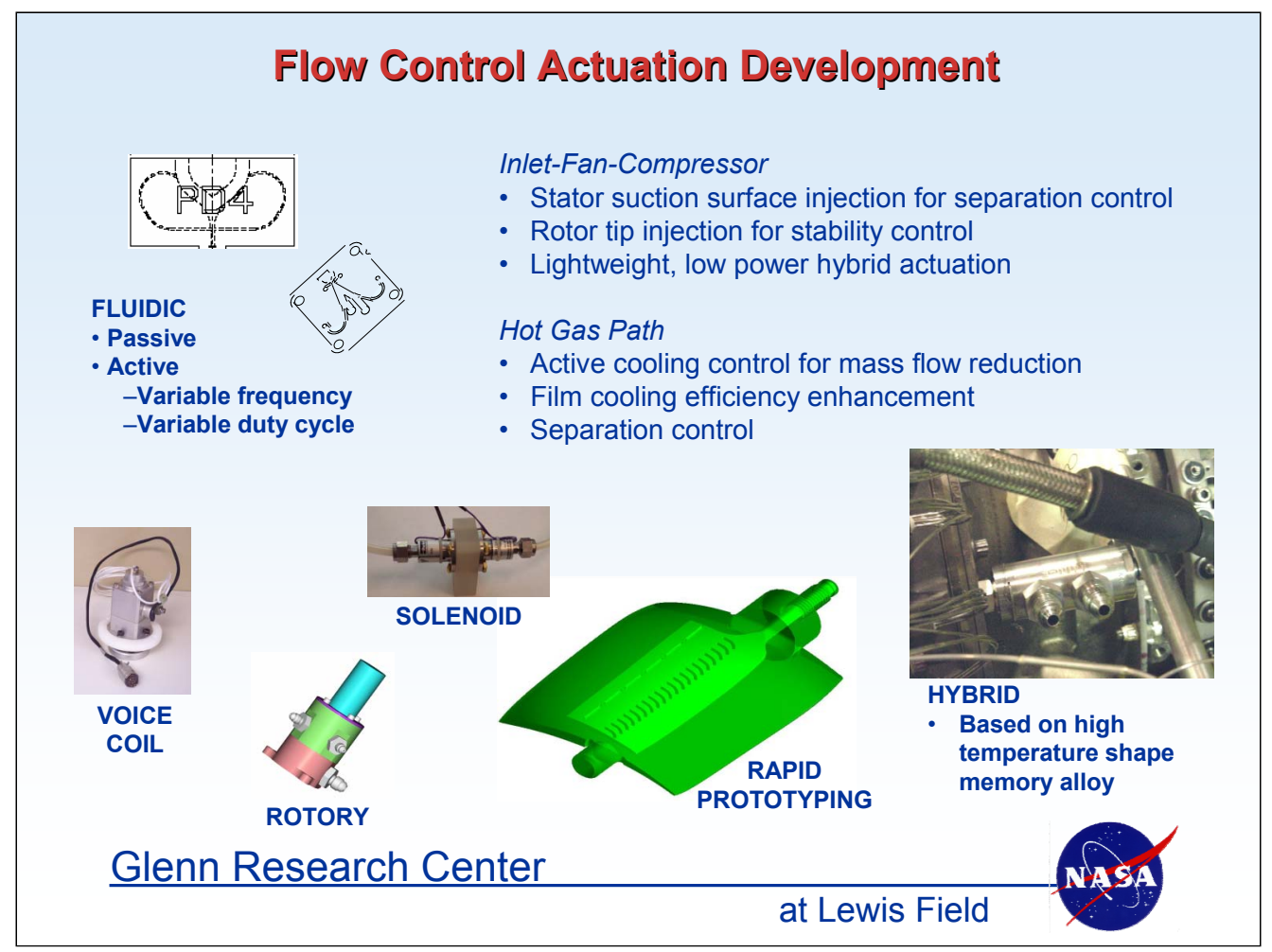

\section{Flow Control Actuation Development}

Currently there are many ongoing research efforts to explore application of flow control to turbomachinery. These include using air injection to affect positive changes in such things as compressor stability, blade loading, and distortion characteristics of inlets. Significantly more effort over a broader range of applications is expected in the future as intelligent engine concepts are developed. A major challenge to exploring and implementing these investigations is the lack of suitable actuation and control elements.

Most current flow control investigations are carried out using the "brute force" method. That is, existing commercial devices or concepts are crudely adapted to enable the exploration of simple first order effects over a limited range of study. Generally, little or no regard for feasibility is considered. The effect is twofold; technology is demonstrated for which there is no known practical means of it being applied in a realworld environment, and quantifying the system benefits are difficult due to lack of information about the impact of implementation.

The key to advancement in flow control technology is in the development of actuation (and sensing) devices which lend themselves to reliable and affordable implementation. NASA GRC is investigating various concepts under a new class of hybrid devices that will lend themselves to integration in engine components where they would be most effective and carry the smallest penalty in terms of weight and power. These devices would be based on new smart materials (high-temperature shape memory alloys and piezoelectrics) for flow control concepts being developed at GRC. Several potential concepts, as depicted in the figure above, are currently under investigation at various stages of development.

Ref: Culley, D.E., Braunscheidel, E.P., and Bright, M.M., "Impulsive Injection for Compressor Stator Separation Control,” AIAA-2005-3633, 41st Joint Propulsion Conference, Tucson, AZ, July 2005. 


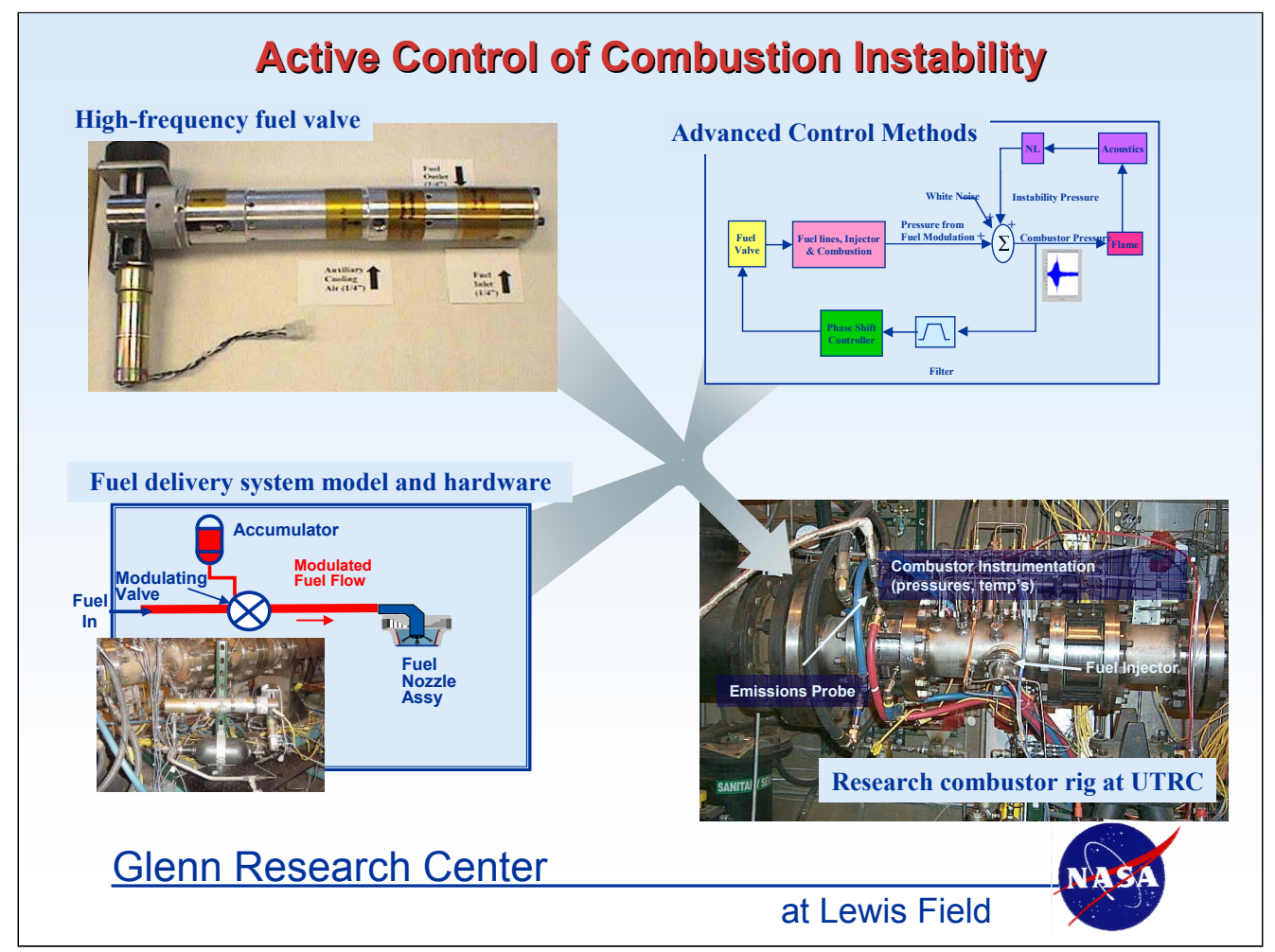

\section{Active Control of Combustion Instability}

As the aircraft engine industry moves towards lean burning combustors in order to meet stringent lowemission requirements, maintaining stability for these combustors can become more problematic. The thermo-acoustic combustion instability issues have already been encountered in lean burning ground-based power generation gas turbine systems. For ground based systems, these issues have been overcome by making ad-hoc design changes or by applying active control. However, dealing with these issues in aeroengines is more challenging since aero-engines operate over a wide range of conditions.

NASA GRC has been working in collaboration with Pratt \& Whitney (P\&W) and United Technologies Research Center (UTRC) to develop and demonstrate technologies for the active suppression of thermoacoustic instability. As part of this effort, a single nozzle combustor rig was developed at UTRC which has the capability to duplicate the thermo-acoustic instability observed in an actual engine test, and also to exhibit a large, lower frequency instability.

In order to suppress instabilities, it is necessary to modulate the fuel flow entering this representative combustor at roughly $500 \mathrm{~Hz}$ (instability frequency which is a function of combustor length). A valve was developed in conjunction with Georgia Tech which is capable of generating the required high frequency modulations in fuel flow. An actuator characterization rig was built up at GRC to be able to identify the dynamic characteristics of the valve so that resulting actuator models can be used for control design development.

Another critical component is the fuel delivery system. An improperly designed fuel delivery system can attenuate perturbations generated by the valve and render the control system ineffective. The fuel delivery system was modeled to better understand these attenuation effects, and open loop testing of the high frequency actuator in the combustion rig was conducted to ensure adequate effectiveness of fuel modulation. 


\section{Active Combustion Control of Instability- Recent Experimental Results}

Large amplitude, low-frequency instability suppressed by 90 percent
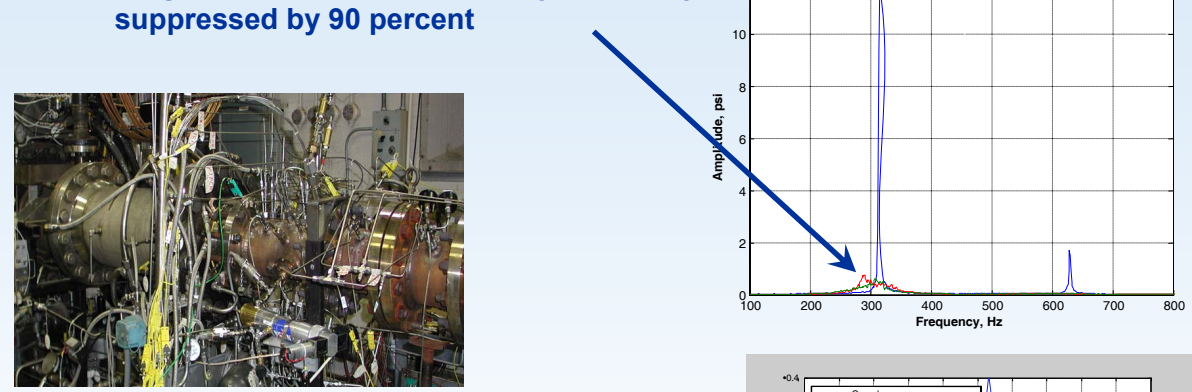

Liquid-fueled combustor rig emulates engine observed instability behavior at engine pressures, temperatures, flows

High-frequency, low-amplitude instability is identified, while still small, and suppressed almost to the noise floor.

\section{Glenn Research Center}

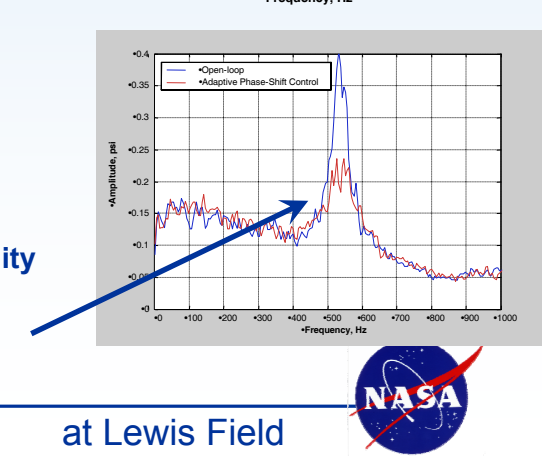

\section{Active Control of Combustion Instability-Recent Experimental Results}

In order to achieve closed loop suppression of the combustion instability, two alternative control methods were developed. These control methods were formulated to deal with the large wideband combustor noise, severe time-delay, and randomness in phase associated with the combustor thermo-acoustic pressure oscillations. Both the controllers use the sensed combustion pressure as input and fuel modulations as output.

Both control methods were initially evaluated against reduced order oscillator models of the combustor pressure in order to verify basic functionality. To provide better fidelity validation of controller performance prior to rig testing, both controllers were then tested against a sectored 1-D model of the combustor rig. The controllers were evaluated on the NASA combustor rig at UTRC and at NASA, and demonstrated significant reduction in instability magnitude for both the high frequency $(\sim 500 \mathrm{~Hz})$ enginelike instability and the lower frequency $(\sim 300 \mathrm{~Hz})$ large amplitude instability. This is first time such instability suppression has been demonstrated in an aero engine-like environment.

Future plans are to investigate the applicability of the instability suppression methodology to advanced ultra-low emissions combustors being designed by NASA and the aerospace industry.

Refs: Kopasakis, G., DeLaat, J.C., and Chang, C.T.: "Validation of an Adaptive Combustion Instability Control Method for Gas-Turbine Engines." AIAA Paper No. 2004-4028 presented at the 40th Joint Propulsion Conference and Exhibit, Ft. Lauderdale, FL, July 2004.

Le, D.K., DeLaat, J.C., Chang, C.T., and Vrnak, D.R., "Model-Based Self-Tuning Multiscale Method for Combustion Control." AIAA Paper No. 2005-3593 presented at the 41st Joint Propulsion Conference and Exhibit, Tucson, AZ, July 2005. 


\begin{tabular}{|} 
Active Turbine Clearance Control Actuator Study \\
Cutaway of high- \\
pressure turbine \\
Requirements
\end{tabular}

\section{Intelligent Control of Turbine Tip Clearance-Control Actuation}

Tight control of the turbine tip clearance at the high pressure turbine is very critical for aircraft engines for both fuel efficiency and on-wing life of the engine. If the clearances are too high, then there is hot gas leakage which is damaging to the engine parts downstream of the hot gas and also there is a decrease in the turbine efficiency resulting in higher fuel consumption. If the clearance is too small, then there is the danger of the turbine blades rubbing against the casing. This can cause damage to the thermal protective coating on the blades requiring the engine to be removed for turbine blade replacement earlier than scheduled.

Active clearance control systems in the high-pressure turbine (HPT) section of commercial aircraft engines are used to close this gap between the turbine blades and shroud. Current clearance control systems rely upon matching the slow-response thermal deflections of HPT components to control clearance at steadystate. Because these modern systems yield, at best, only modest benefits, it is necessary to employ faster active clearance control systems.

A study has been conducted to investigate the actuation and control requirements of an active clearance control system in a generic commercial turbofan engine. Using a feedback signal from high-bandwidth clearance probes, the actuator will move the shroud in the high pressure turbine section toward and away from the blades in order to maintain a certain clearance set point. The requirements for the actuators and the three actuator concepts that were investigated for such a purpose are shown in the figure. The ultimate goal of this research is to design and build actuators from each category, conventional and smart materials, for testing on the NASA GRC active clearance control test rig.

Ref: DeCastro, J.A., Melcher, K.J., "A study on the requirements for fast active turbine tip clearance control systems," 40th Joint Propulsion Conference and Exhibit, AIAA-2004-4176, Ft. Lauderdale, FL, July 2004. 


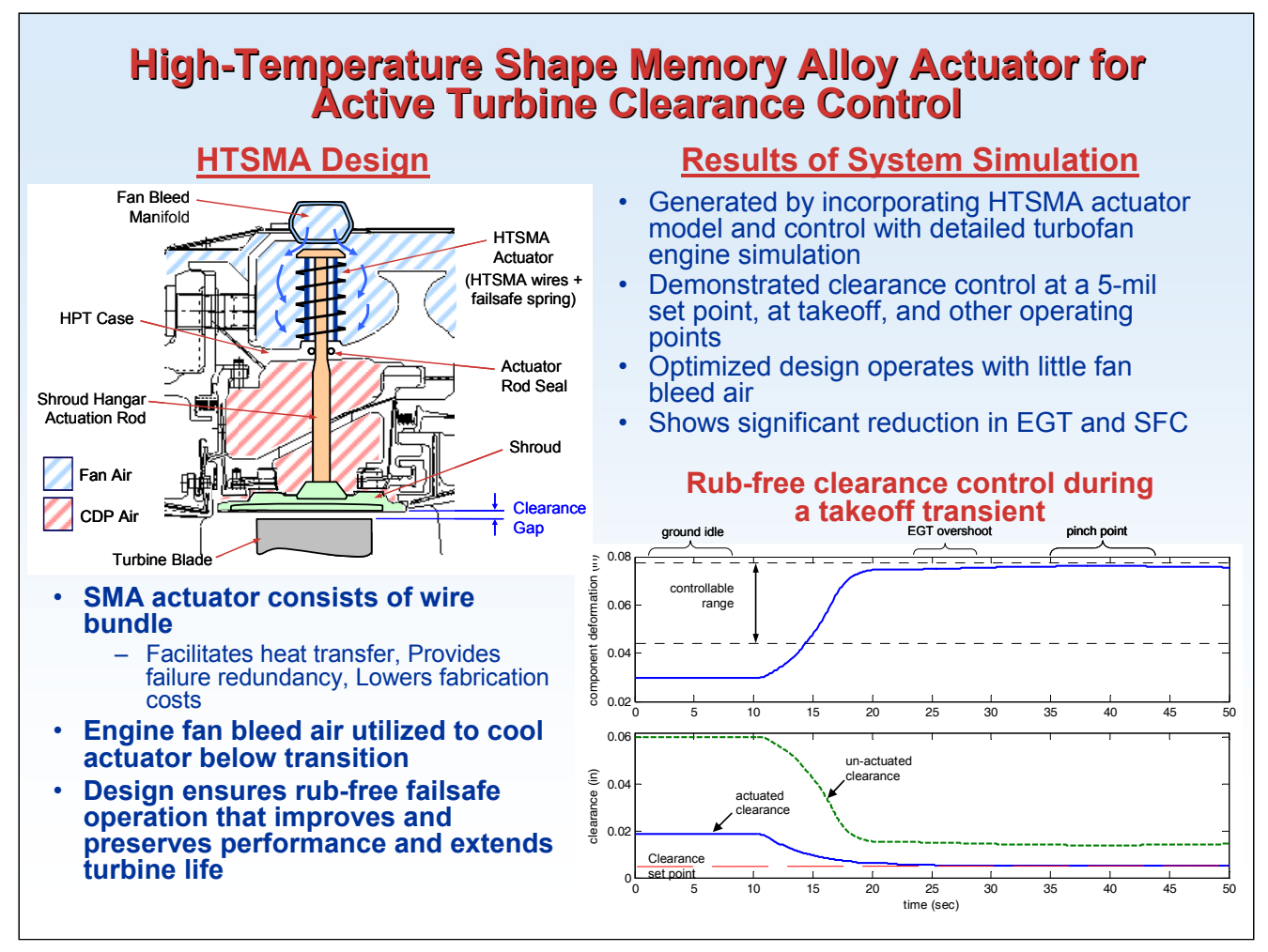

\section{Shape Memory Alloy Actuation for Clearance Control}

A study to explore the feasibility of high temperature shape memory alloy (HTSMA) actuators for active clearance control in the high-pressure turbine (HPT) was completed. Shape memory alloys are promising actuation candidates because they have order-of-magnitude higher energy densities than other advanced actuators - an attractive characteristic in meeting stringent weight and size goals of a flight-worthy actuator package. They are also preferred because they can potentially operate without the addition of bulky power amplifiers, thereby minimizing energy consumption. An HTSMA actuator concept was developed for application in the NASA Active Clearance Control Test Rig. The actuator concept consists of several parallel HTSMA wires (Ni30Pt20Ti50) that longitudinally expand or contract with changes in temperature. For implementation in a high-bypass turbofan engine, each actuator must counteract large time-varying loads, displace at least 0.033 in., and be physically robust to the extreme temperatures of the HPT.

A high-fidelity model of the HTSMA actuation system concept was developed to perform an optimal design of the actuator and verify that the design is sufficient to perform clearance control over the engine's operating envelope. Design results show that HTSMA design lengths of less than 2 in are possible for the actuator to fit within the limited space outside the HPT case. Transient clearance control simulations in a testbed engine simulation reveal that a design consisting of 10 wires of 0.09 -in. in diameter is adequate in providing rub-free tracking during rapid operating point transitions, such as takeoff. Additionally, it was demonstrated that a linear PID control law with anti-windup protection is sufficient for precise shroud control with the nonlinear actuator across the operating envelope.

Ref: DeCastro, J.A., Melcher, K.J., and Noebe, R.D., "System-level design of a shape memory alloy actuator for active clearance control in the high pressure turbine," 41st Joint Propulsion Conference and Exhibit, AIAA-2005-3988, Tucson, AZ, July 2005. 


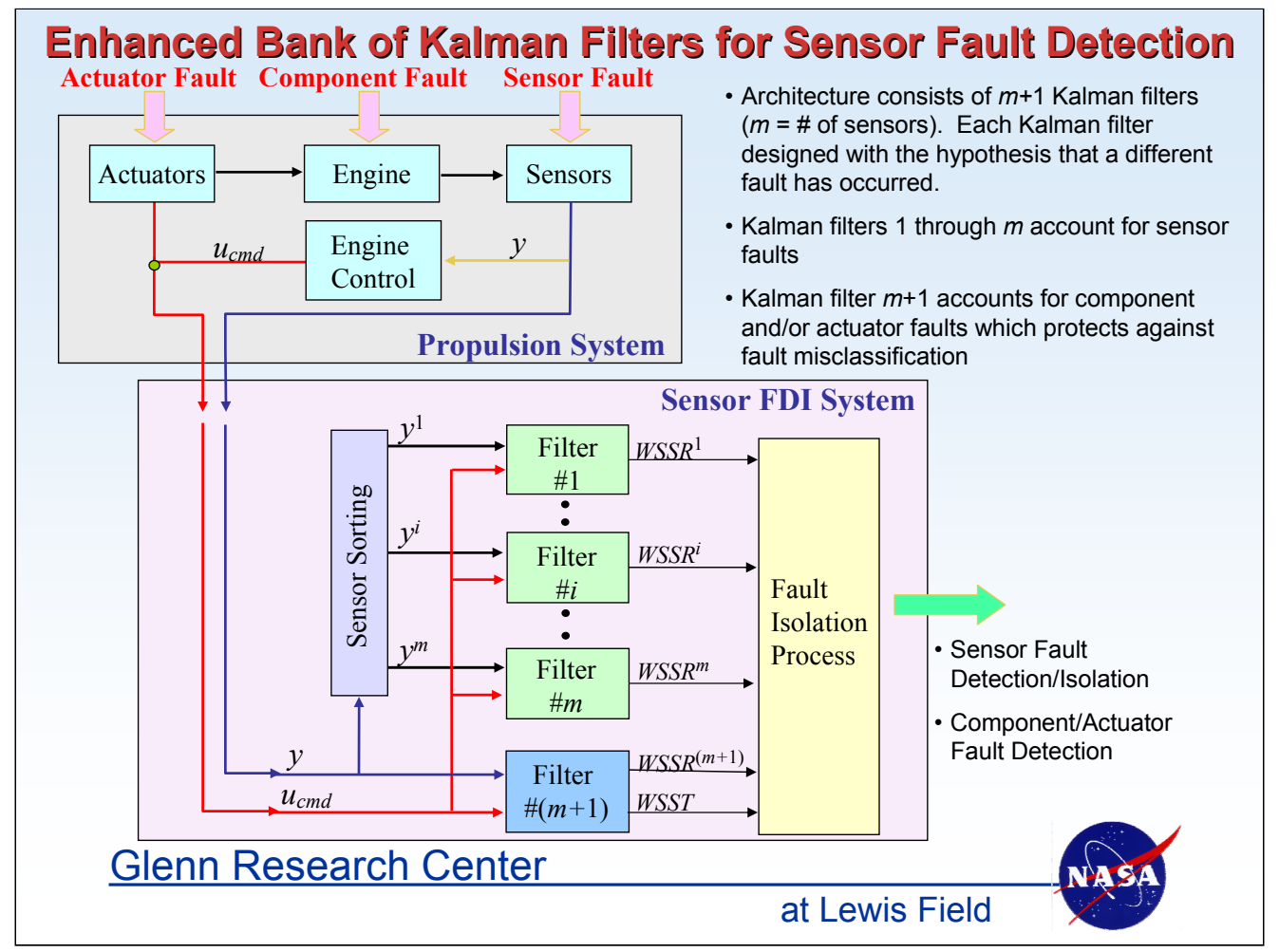

\section{Enhanced Bank of Kalman Filters for Sensor Fault Detection}

In-flight sensor fault detection and isolation (FDI) is critical to maintaining reliable engine operation during flight. However, sensor FDI systems must be robust to other faults, that can occur during flight, in order to avoid false alarms, missed detections, or misclassifications. To address the above issue, an enhanced bank of Kalman filters approach to sensor fault detection was developed and its performance and robustness was demonstrated in a simulation environment.

The bank of Kalman filters is composed of $(m+1)$ Kalman filters where $m$ is the number of sensors being used by the control system and thus in need of monitoring. Each Kalman filter is designed based on a unique fault hypothesis so that it will be able to maintain its performance if the particular fault scenario, hypothesized by that particular filter, takes place. Each of the $m$ Kalman filters is designed to estimate the engine state variables and a specific set of sensor measurements using $(m-1)$ sensors. The sensor which is not used by a particular filter is the one being monitored by that filter for sensor fault detection. One additional Kalman filter, $m+1 s t$, is designed for the detection of component and/or actuator faults. This additional Kalman filter distinguishes component and/or actuator faults from sensor faults; therefore it makes the sensor FDI system robust to component and actuator failure.

With the above FDI architecture, each Kalman filter generates a fault indicator signal which indicates the existence of faults in the system being monitored. When a sensor or component/actuator fails, all Kalman filters will generate large fault indicator signals except for the one which is using the correct hypothesis. Consequently, detection and isolation of sensor faults or detection of component/actuator faults can be achieved with high reliability. 


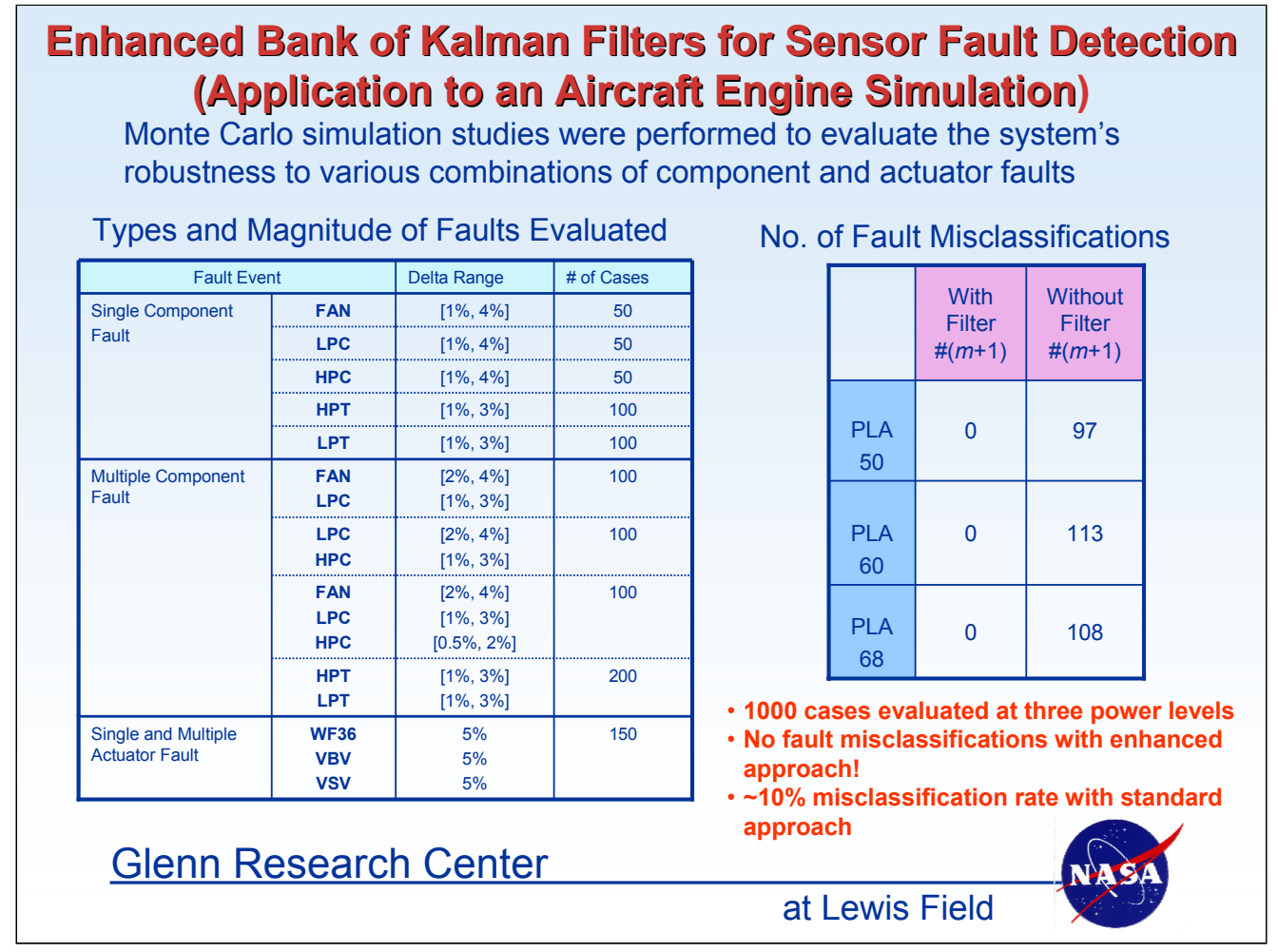

\section{Enhanced Bank of Kalman Filters for Sensor Fault Detection (Application to an Aircraft Engine Simulation)}

The bank of Kalman filters approach was applied to a nonlinear commercial aircraft engine simulation. Its performance was evaluated at multiple power settings during cruise operation. The system was found to perform extremely well in diagnosing sensor faults while being robust against missed detections, false alarms, and fault misclassifications.

The performance of the enhanced bank of Kalman filters was evaluated in the following four categories: 1) missed detections, 2) false alarms, 3) misclassifications, and 4) robust sensor fault isolation. It was found to perform extremely well in all areas. Particularly encouraging results were observed in the system's robustness to misclassifications, which are considered as the worst scenario that can happen during flight. At three different power settings, the sensor FDI system was tested with 1000 different events of component or actuator faults in the simulation environment. The sensor FDI system did not classify any of these component or actuator faults as a sensor fault, thus avoiding any misclassification scenarios.

Through these evaluations, the enhanced bank of Kalman filters technique has demonstrated its performance and robustness, indicating that this technology is promising for the safety enhancement of aircraft gas turbine engines.

Ref: Kobayashi, T., and Simon, D.L., "Evaluation of an Enhanced Bank of Kalman Filters for In-Flight Aircraft Engine Sensor Fault Diagnostics," ASME Paper GT2004-53640, Turbo Expo 2004, Vienna, Austria, June 2004. 


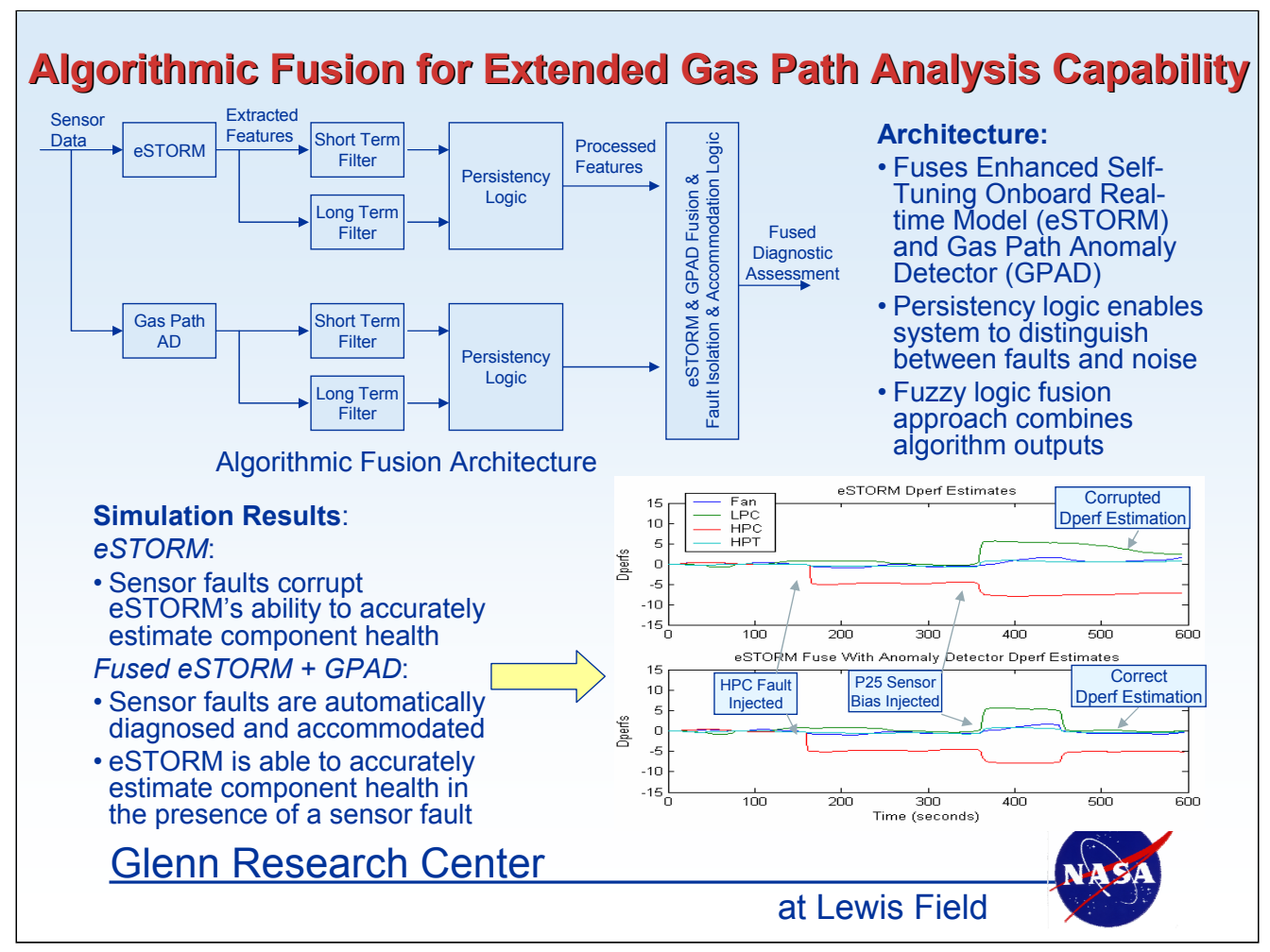

\section{Algorithmic Fusion for Extended Gas Path Analysis Capability}

A wealth of aircraft turbine engine data is available from a variety of sources including on-board sensor measurements, operating histories, and component models. Furthermore, additional data will become available, as advanced prognostic sensors are incorporated into next generation gas turbine engine systems. The challenge is how to maximize the meaningful information extracted from these disparate data sources to obtain enhanced diagnostic and prognostic information regarding the health and condition of the engine.

To address this challenge, NASA and Pratt \& Whitney $(\mathrm{P} \& W)$ are collaborating to develop Information Fusion technology. Under this effort a modular hierarchical information fusion architecture was developed. To demonstrate the efficacy of this architecture, a fusion demonstration of two gas path analysis algorithms, the Enhanced Self-Tuning Onboard Real-time Model (eSTORM) and a neural network-based Gas Path Anomaly Detector (GPAD), was performed. The fusion of these two algorithms was synergistic because each algorithm had particular strengths which complemented the other algorithm's deficiencies. The architecture used to fuse these two algorithms is shown above. This fusion allowed the system to detect and isolate both sensor and component faults. Furthermore, once a sensor fault is detected, it is accommodated by replacing the faulty physical measurement with a estimated value. This allows the system to continue to accurately estimate component performance even in the presence of a sensor fault.

Simulation results shown above compare the effectiveness of this fusion approach versus using eSTORM as a stand alone diagnostic technique. Shown for each case are eSTORM estimates of module performance deltas, which are referred to as Dperfs. Dperfs represent an efficiency degradation in the engine's major components. The eSTORM alone is not able to accommodate for the corrupted sensor input and incorrectly attributes it to component degradation, while the fused system is able to discern that a sensor fault has occurred, and it is accommodated by returning the eSTORM Dperf estimates to their correct pre-sensor bias values. 


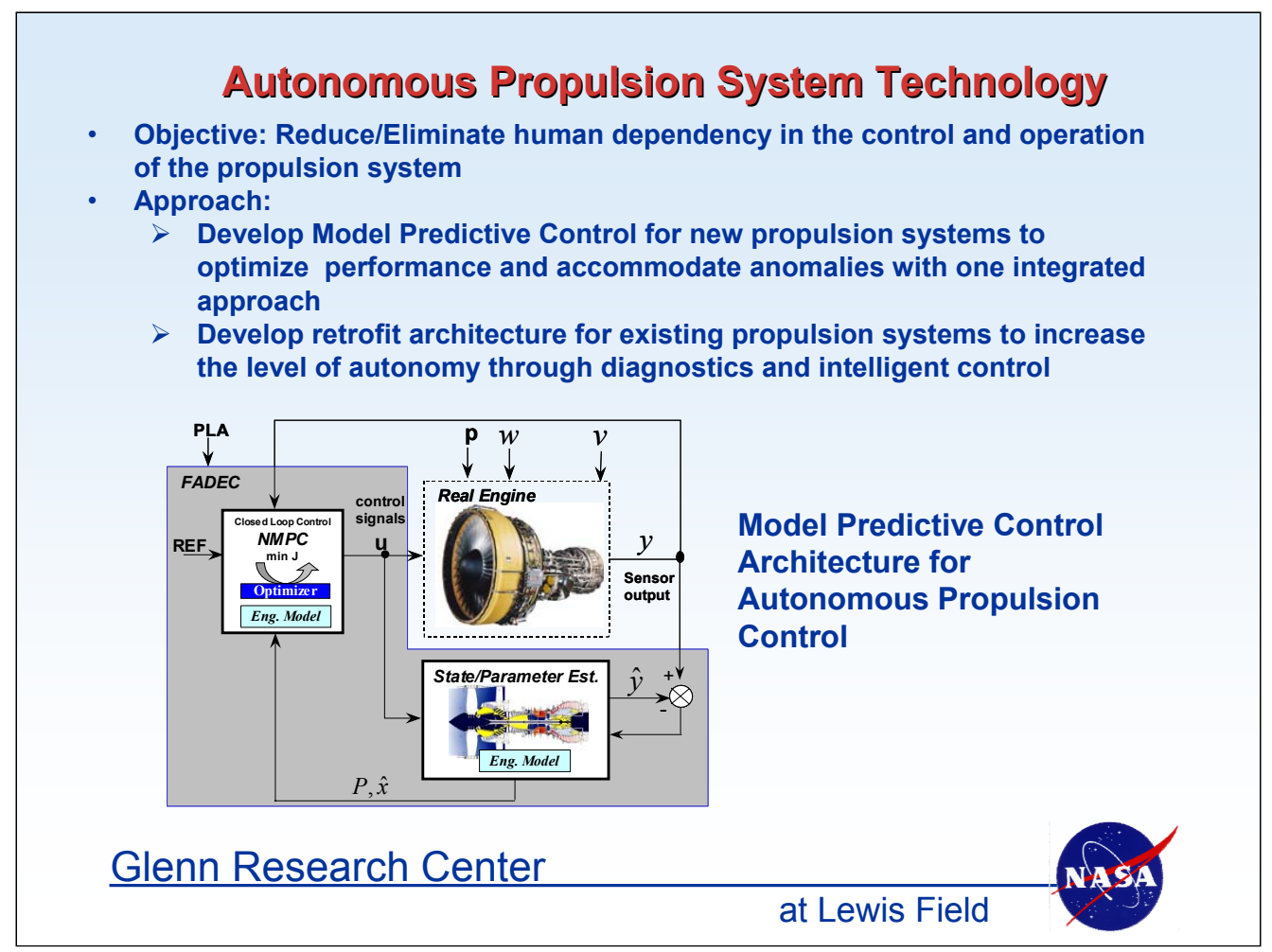

\section{Autonomous Propulsion System Technology}

In the current aviation system airplanes, the pilot serves the critical function of integrating the propulsion system control with the flight control. The only exceptions to this are the "autothrottle" system which is deployed as part of the auto-pilot and is limited to operation at cruise under fair weather conditions, and the "autoland" system which is limited to landing under favorable conditions. Developing technologies for autonomous accomplishment of propulsion system control, diagnostics and prognostics functions is critical for enabling highly or fully autonomous operation of airplanes.

NASA GRC had initiated a multi-year research effort for developing and demonstrating Autonomous Propulsion System Technology (APST). Due to various programmatic reorganizations within NASA, the APST project was downscoped to focus on the two elements identified in the above figure.

The Model Predictive Control (MPC) architecture and methodology development work is being done by General Electric Aircraft Engines in collaboration with NASA researchers. At the core of the overall technology development is a real-time embedded transient engine model. This model is used in the MPC strategy to provide an optimized control for the engine based on the desired operation mode. The MPC is designed to minimize the Specific Fuel Consumption (SFC) during steady-state engine operation, and to track a desired transient reference thrust profile $(\mathrm{FN})$ while minimizing engine temperatures during transient operations; e.g., during idle-takeoff. The overall architecture was designed to integrate and automate the engine controls, estimation, fault diagnostics and accommodation into one seamless setup, thereby reducing pilot workload. Research is currently underway to develop efficient computation methods to implement MPC in order to allow real-time control implementation.

Ref: Brunell, B.J., Viassolo, D.E., and Prasanth, R., "Model-Based Control Adaptation and Optimization for Critical Mission Requirements," GT2004-53780, Proceedings of the 2004 ASME Turbo Expo, Vienna, Austria, 2004. 


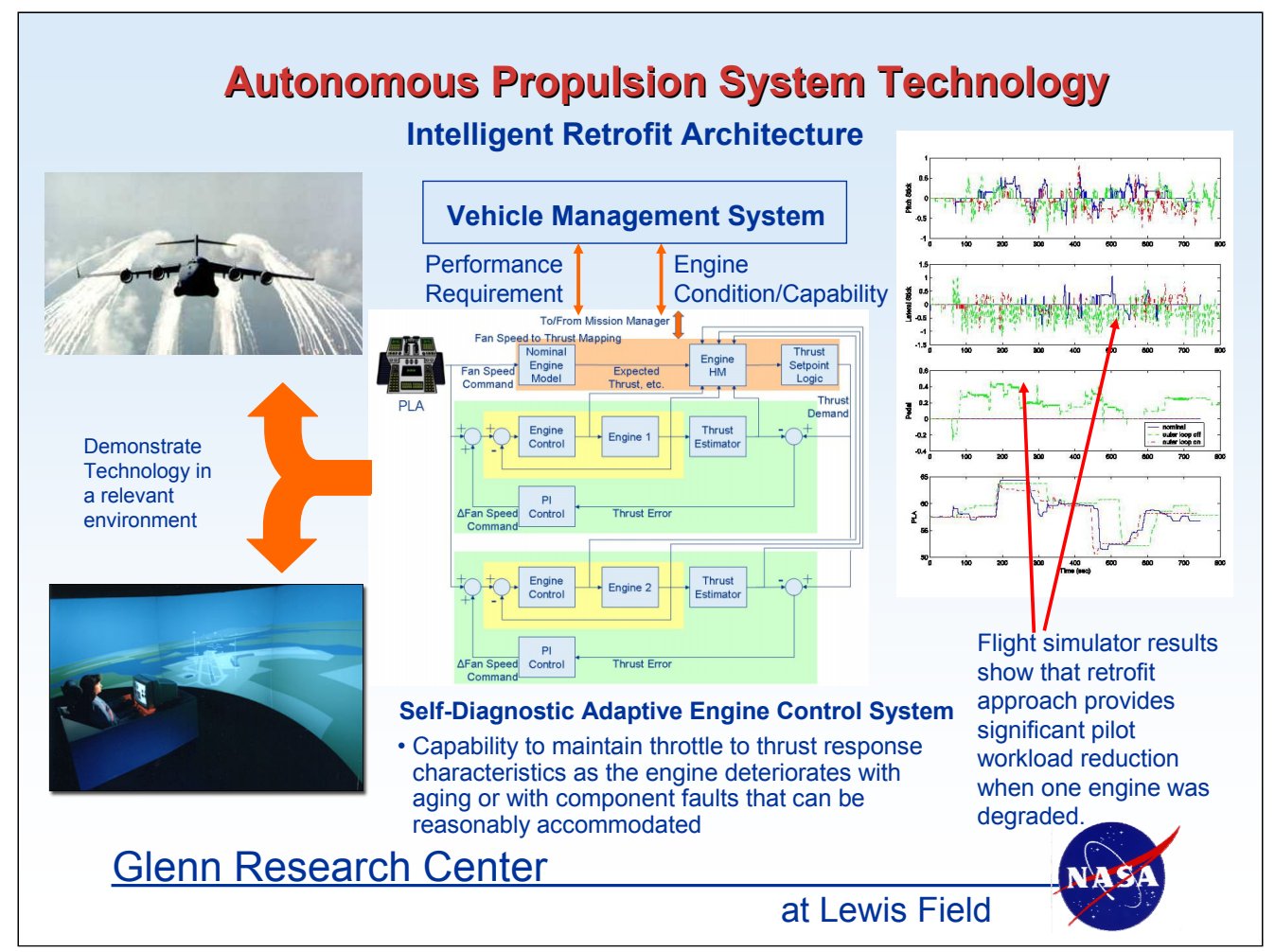

APST - Intelligent Retrofit Control Architecture

A typical engine inner-loop control architecture employs fuel flow to control fan speed, which is assumed to be highly correlated to engine thrust. However, as the engine ages, the relationship between fan speed and thrust changes, thus changing the thrust response to throttle input. If all engines on a multi-engine aircraft do not have the same throttle-to-thrust relationship, it can result in a thrust imbalance, producing unwanted yaw, which requires pilot intervention to correct. The figure shows retrofit architecture for intelligent turbofan engine control and diagnostics that changes the outer loop fan speed reference signal to accommodate the affect of change in fan speed to thrust relationship. This architecture includes a thrust estimator the output of which is compared with the thrust response of a "nominal" engine to generate the corrected fan speed reference.

The Intelligent Control contains the parts of the control structure that evaluate the safety, performance, and capabilities of the engines. It takes input from multiple engines (control signals, sensed variables, thrust estimate, etc.) to determine each engine's current health and fitness for the mission. It also generates the outer loop thrust command that both engines follow. If the Intelligent Control determines that the condition of an engine is such that corrective action is beyond the scope of the propulsion control (for instance, a problem that might compromise the mission) it communicates this information to the Mission Manager. The intelligent retrofit architecture was demonstrated for the steady-state thrust response case in fixed base piloted simulation for a commercial aircraft/engine simulation. With the intelligent control adjustment on, the pilot did not have to retrim the plane or adjust the throttles individually to maintain heading, thus resulting in reduced pilot workload. The thrust estimator tracked the actual thrust of the degraded engine and enabled direct thrust control.

Ref: Litt, J.S., Turso, J.A., Shah, N., Sowers, T.S., and Owen, A.K., "A Demonstration of a Retrofit Architecture for Intelligent Control and Diagnostics of a Turbofan Engine," AIAA-2005-6905, Infotech@Aerospace, Arlington, VA, September 2005. 


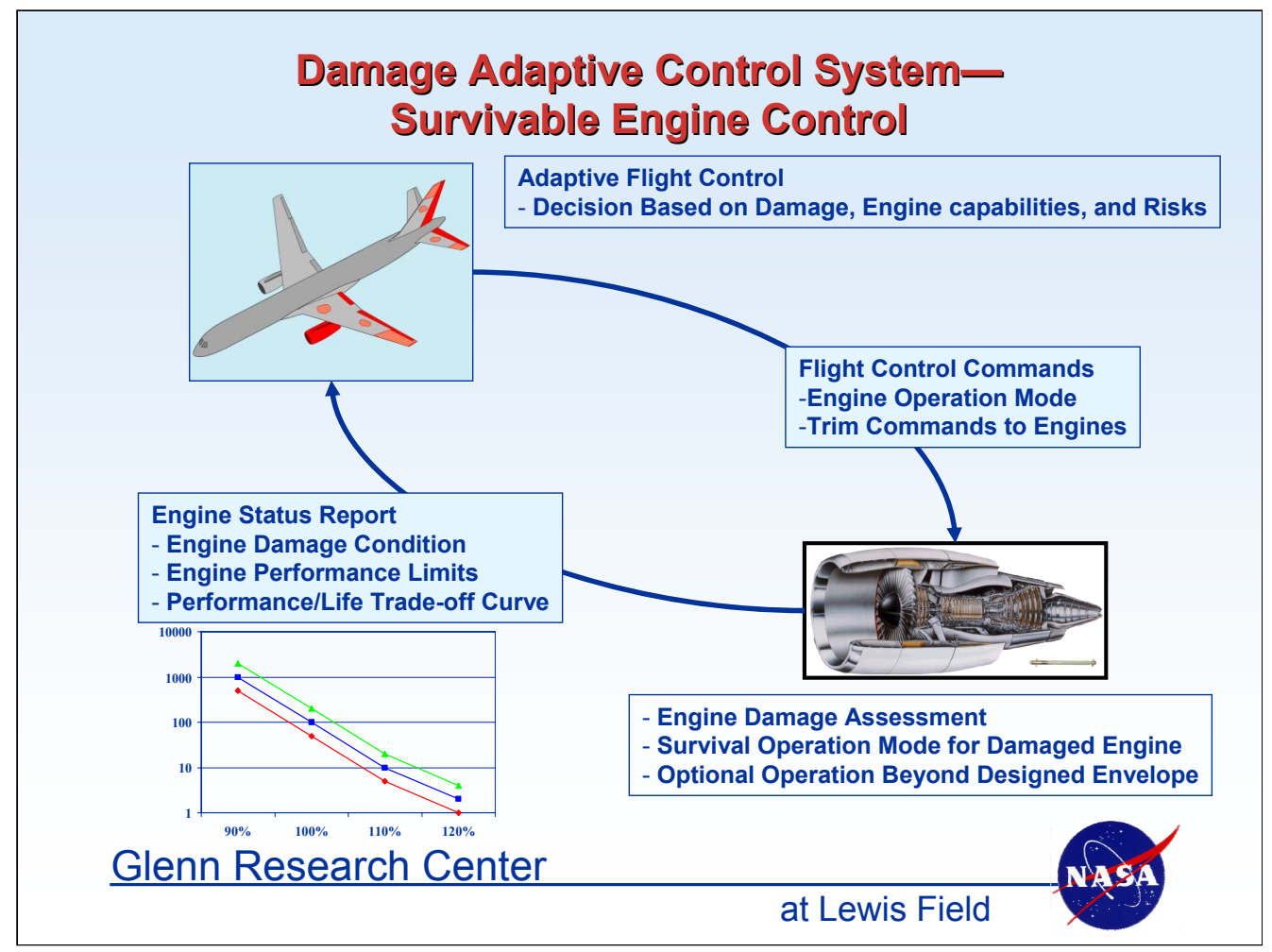

\section{Damage Adaptive Control System-Survivable Engine Control}

As part of the effort to increase aircraft safety and enable the capability to land an aircraft safely in the presence of airframe or engine damage due to internal or external causes, NASA has initiated research in Damage Adaptive Control System (DACS). This is a multi-center effort including Ames Research Center, Dryden Flight Research Center, Glenn Research Center, and Langley Research Center, and includes plans to demonstrate DACS technology on a flight test-bed.

The GRC role is to develop technologies for survivable engine control that will enable reconfiguration of the engine control based on an assessment of damage, remaining capabilities and required performance in terms of thrust and thrust rate and desired time of operation. The engine reconfigurable control technology is being developed for two distinct scenarios: i) Only the airframe is damaged and the engines have full performance capability as designed; ii) One or more engines are damaged with the possibility of the airframe also sustaining some damage.

For the first scenario, the focus is to determine what additional performance requirements are placed on the propulsion system to be able to achieve the desired aircraft control capability, and how to meet these requirements. Studies are underway to determine how these enhanced performance requirements can be achieved by overriding some of the engine limits embedded in the control logic. It is important to understand the affect of overriding these limits on performance and usable engine life in order to determine how the engine control can be reconfigured without causing any additional safety problems.

For the second scenario, the focus is on developing technologies to be able to accurately assess the damage to the engine and remaining performance capability. This assessment can be used to determine whether to continue operating the engine at whatever performance it is able to deliver or to shut it down for safety. Damage detection algorithms are currently being developed and validated against existing experimental and operational data. 


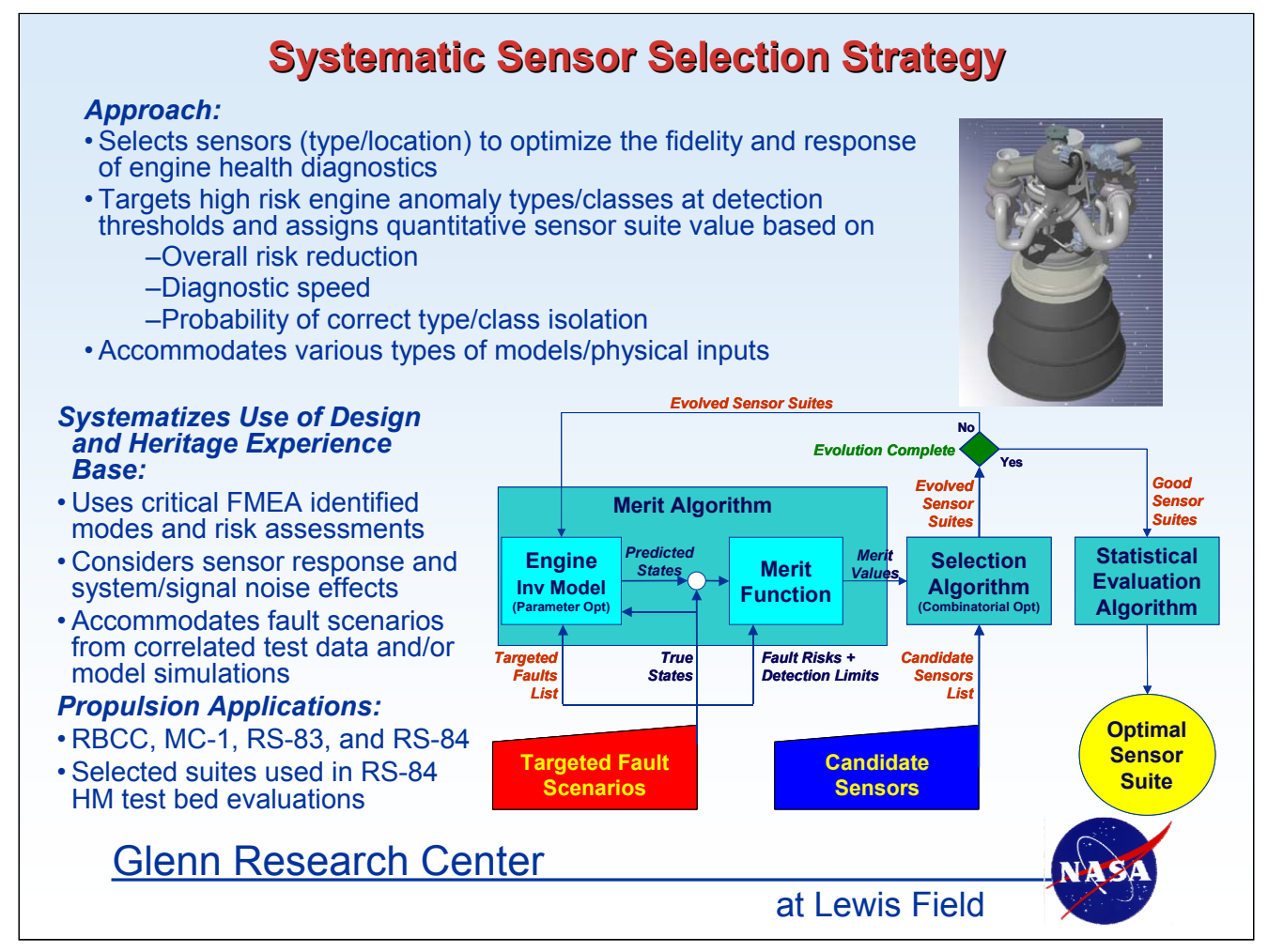

\section{Systematic Sensor Selection Strategy}

Sensor data are the basis for performance and health assessment of most complex systems. Careful selection and implementation of sensors is critical to enable high fidelity system health assessment. A model-based procedure that systematically selects an optimal sensor suite for overall health assessment of a designated host system was developed by the Controls and Dynamics Branch at NASA GRC. This procedure, termed the Systematic Sensor Selection Strategy (S4), was developed to enhance design phase planning and preparations for in-space propulsion health management systems (HMS).

S4 can be logically partitioned into three major subdivisions: the knowledge base, the down-select iteration, and the final selection analysis. The knowledge base required for productive use of S4 consists of system design information and heritage experience together with a focus on components with health implications. The sensor suite down-selection is an iterative process for identifying a group of sensors that provide good fault detection and isolation for targeted fault scenarios. The process is composed of three basic components: a system health diagnostic model (i.e., an inverse model), a merit algorithm, and a selection algorithm. In the final selection analysis, the statistical evaluation algorithm provides a final robustness test for each down-selected sensor suite.

The S4 approach was applied for sensor selection for health management of the Rocketdyne RS-84 engine concept under the NASA Next Generation Launch Vehicle technology program. The process identified a suite of 22 sensors from a candidate set of 59 sensors that maximized risk reduction potential. In addition to obvious safety benefits, the identification of health assessment enabling sensors early in the design phase helps avoid unnecessary engine instrumentation and the need for costly system retrofits and recertification.

Ref: Santi, L.M., Sowers, T.S., and Aguilar, R.B., "Optimal Sensor Selection for Health Monitoring Systems," 41st Joint Propulsion Conference and Exhibit, AIAA-2005-4485, July 2005. 


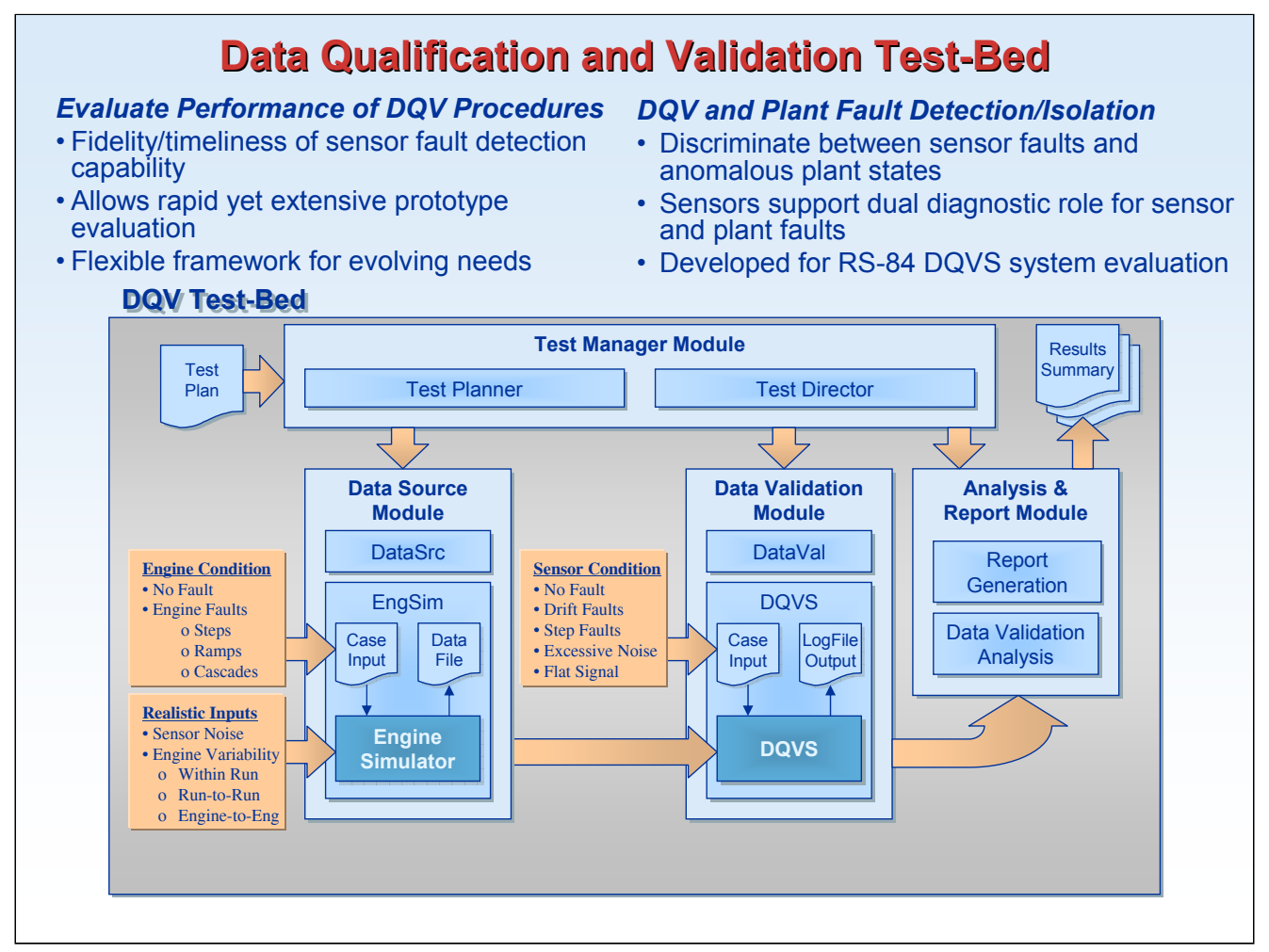

\section{Data Qualification and Validation Test-Bed}

On-line data validation is a performance-enhancing component of modern control and health management systems. It is essential that performance of the data validation system be verified prior to its use in a flight-rated control and health management system. A new Data Qualification and Validation (DQV) Test-Bed application was developed to provide a systematic test environment for this performance verification. The DQV Test-Bed was used to evaluate a model-based data validation package being employed as the data validation component of a rocket engine health management (EHM) system.

Four major modules compose the test-bed framework. The Test Manager Module defines the test conditions and controls the overall execution of the test sequence. Test data is provided by the Data Source Module. The Data Validation Module manages the system under test (SUT). The Analysis and Reporting Module evaluates the output from the SUT with the known test conditions and generates a series of reports summarizing the results.

The DQV Test-Bed has proved to be an effective tool for cost effective and comprehensive testing of health monitoring systems. It provides an efficient avenue for assessing the strengths and weaknesses of prototype data validation and fault detection systems by improving the understanding of those systems' capabilities and trade-offs. The DQV Test-Bed provides a potentially useful and important element of the necessary infrastructure to iteratively develop and flight-qualify future propulsion health monitoring systems.

Ref: Sowers, T.S., Santi, L.M., and Bickford, R.L., "Performance Evaluation of a Data Validation System," 41st AIAA/ASME/SAE/ASEE Joint Propulsion Conference and Exhibit, AIAA-2005-4486, July 2005. 


\section{Integrated System Health Management-GRC Technologies}

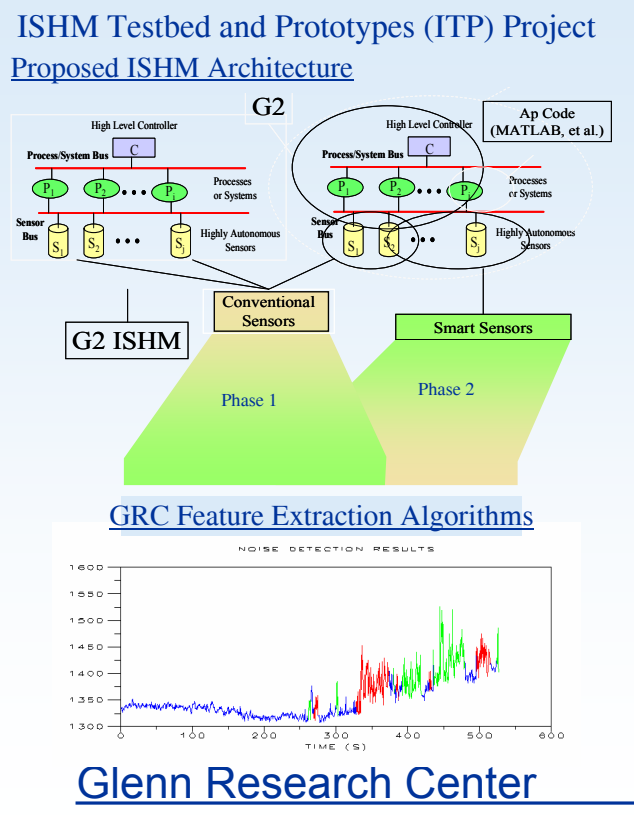

ISHM for Intelligent Modular Systems Project

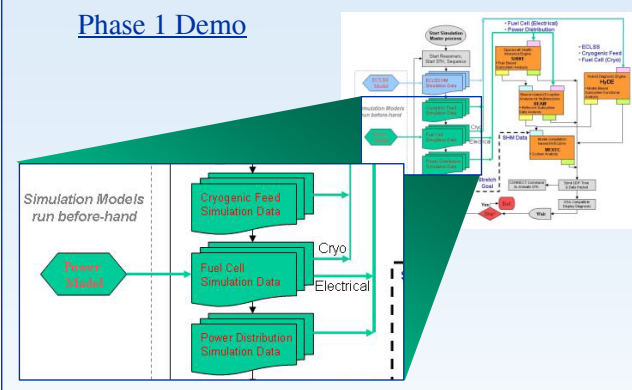

Results from Cryogenic Feed System Simulation

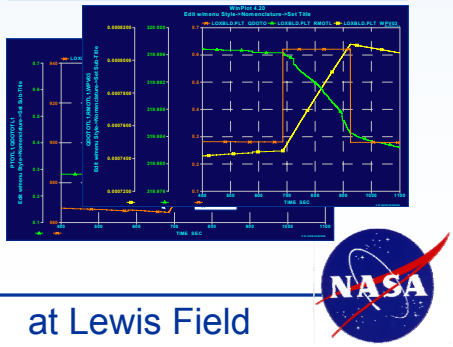

\section{Integrated System Health Management_GRC Technologies}

NASA GRC is currently supporting both Integrated System Health Management (ISHM) research efforts competitively awarded under NASA's Exploration Systems Research and Technology program. As a member of these research teams, NASA GRC is providing health management technologies that are critical to the success of these projects.

The first ISHM research effort is the "ISHM Test-bed and Prototype" (ITP) project, led by NASA JSC and SSC. NASA GRC's role in this research is to provide anomaly detection; data, information, and knowledge fusion in the context of an integrated system-of-systems model. Specifically for the Phase 1 period, GRC is developing feature extraction algorithms that provide an event detection capability for NASA SSC Integrated Health Management and Intelligent Networked Elements test-bed. These algorithms have been streamlined and tested for real-time detection of specific features or events within data. Future efforts will involve integrating the algorithms into a simulation-based health management testbed; and eventually embedded in a smart sensor platform for hardware implementation and testing.

The second ISHM research effort is an externally led project, ISHM for Intelligent Modular Systems. GRC role in this project is to support the development and demonstration of an open, modular, and "plug-andplay" health management architecture. GRC is the primary developer of the power and propulsion health management systems for this project. During Phase 1, GRC is developing fault simulations of an Apollolike spacecraft power distribution system for the demonstrations. For the Phase 2 research, GRC will be responsible for designing and implementing representative health management systems for both the power and propulsion subsystems that will demonstrate the capabilities and benefits of the ISHM architecture developed under this project.

Ref: Maul, W., Park, H., Schwabacher, M., and Watson, M., et. al., "Intelligent Elements for the ISHM Testbed and Prototypes (ITP) Project," NASA/TM-2005-213849. 


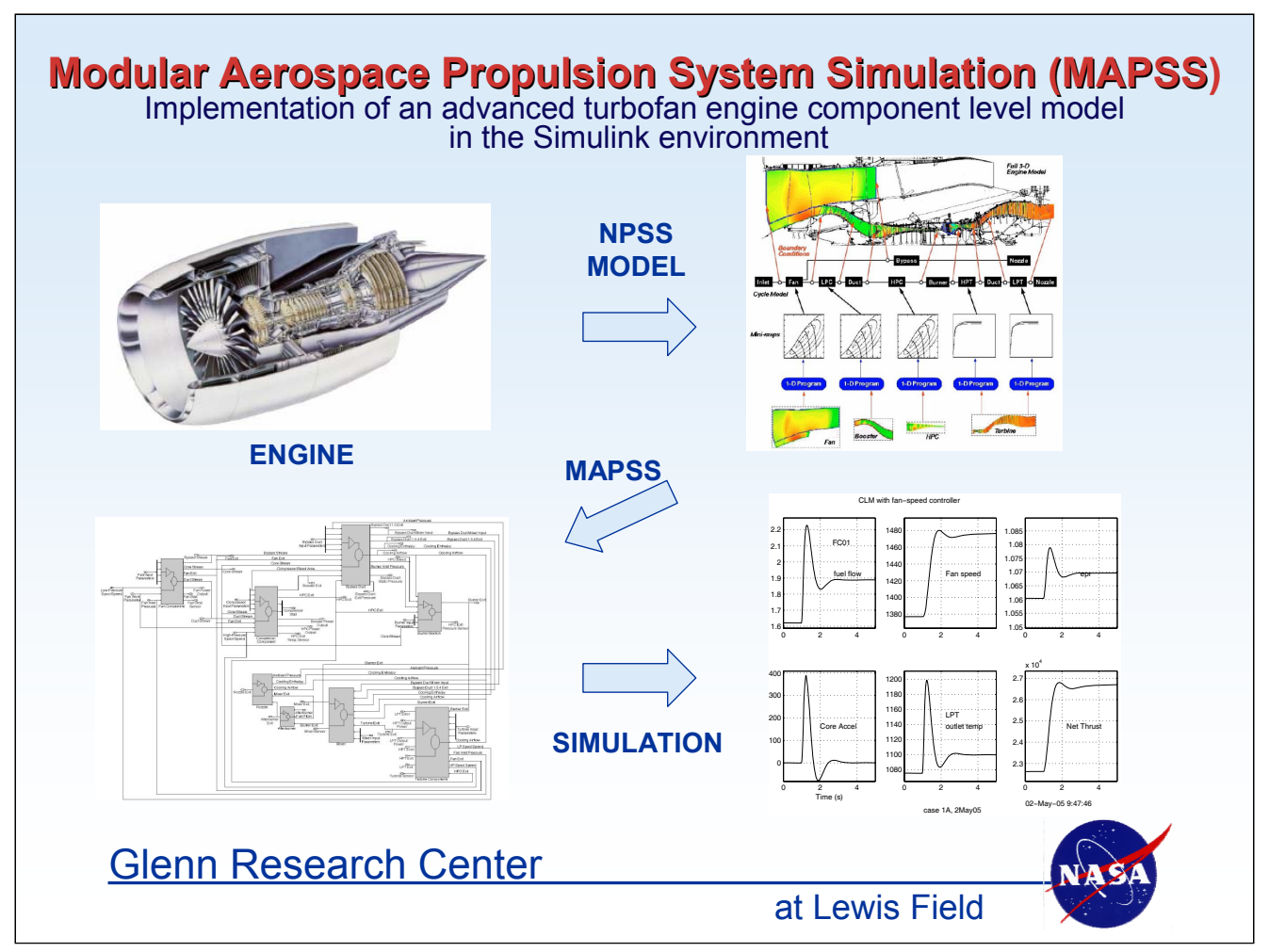

\section{Modular Aerospace Propulsion System Simulation (MAPSS)}

Development and validation of the various controls and diagnostics technologies discussed so far requires the availability of a 1-D transient engine simulation. Typically, the engine simulation cycle decks developed by industry are proprietary in nature, and are not available for NASA to share with universities or small businesses conducting controls research. NASA has developed the Numerical Propulsion Simulation System (NPSS) which has now become the default simulation system being used by aerospace industry. However, the NPSS system is geared more towards doing cycle analysis or detailed engine component design, and is not "user-friendly" for controls research.

To overcome these shortcomings, the Controls and Dynamics Branch has developed the Modular Aerospace Propulsion System Simulation (MAPSS) capability to model an aircarft engine in a graphical simulation environment called Simulink. This graphical environment is the one used by most control designers for development and evaluation of control logic. The MAPSS simulation of a turbofan engine representative of an advanced fighter aircraft engine was developed earlier and is available for free through the NASA GRC software repository at https://technology.grc.nasa.gov/software/index.asp.

More recently, as depicted in the figure above, a MAPSS version representing a commercial 90,000 lb thrust engine, originally modeled in NPSS, has been developed. This MAPSS simulation is expected to be available for public release in the near future. An extensive Graphical User Interface (GUI) capability is being added to MAPSS which will allow the user to generate linear models, design controllers using the K$\mathrm{Q}$ (or Edmunds) model-matching approach, and perform closed-loop system evaluations.

Ref: Parker, K., and Guo, T., "Development of a Turbofan Engine Simulation in a Graphical Simulation Environment," NASA/TM-2003-212543, August 2003. 


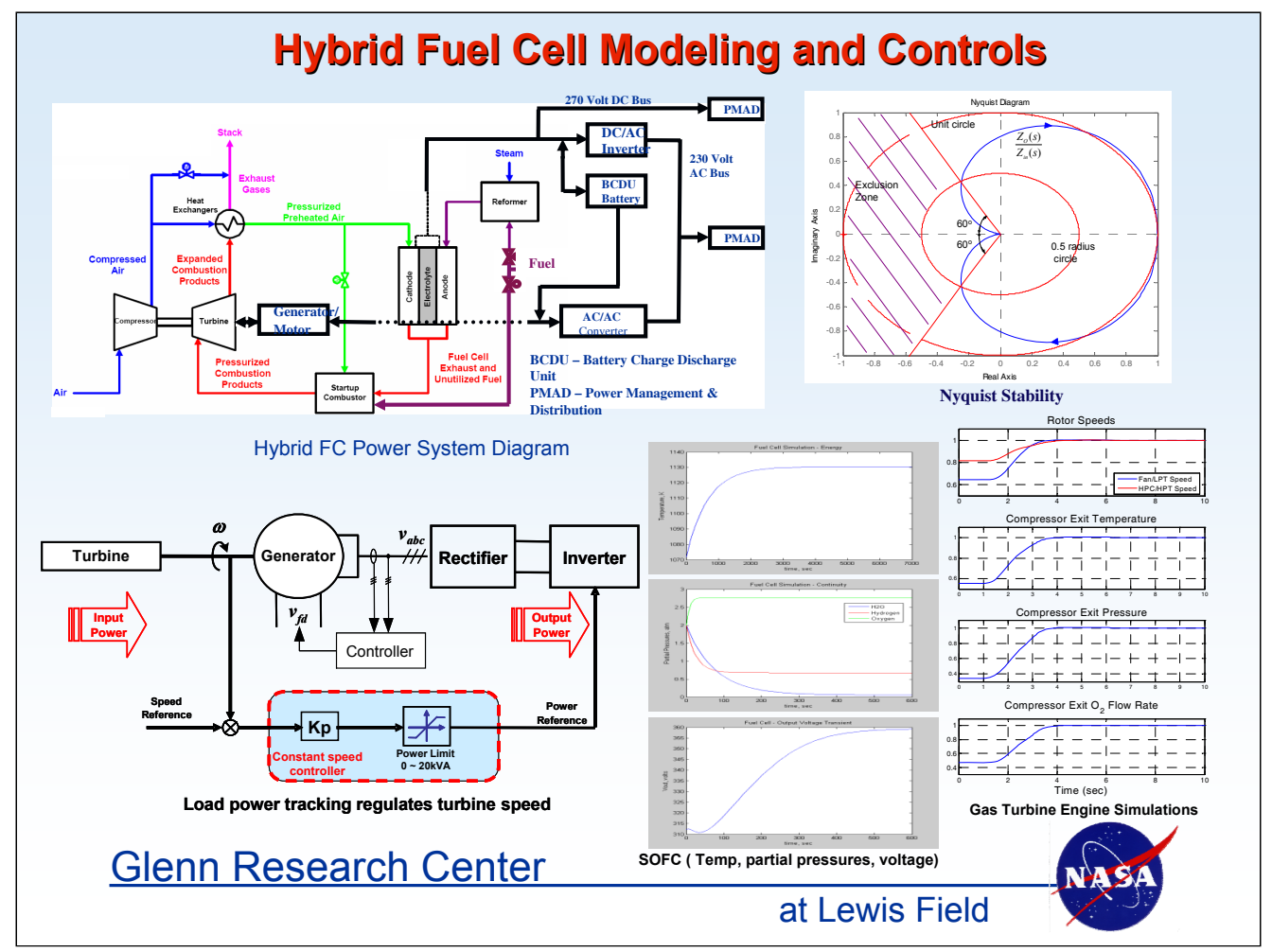

\section{Hybrid Fuel Cell Modeling and Controls}

As the aviation industry moves towards zero emissions and more quiet aircraft, fuel cells are sought as the technology that can deliver on these high expectations. NASA GRC has been working on Aircraft Fuel Cell Power Systems technologies, which involves conceptual design studies, fuel cell and reformer materials research, and various fuel cell system testbed operations and research. As part of this effort, the Controls and Dynamics Branch is involved in the dynamic modeling aspects and controls of the Hybrid Fuel Cell electrical power generation system. The challenge is to understand the dynamics of this complex multi-discipline system, and design distributed controls that take the system through its operating scenarios in a stable and safe manner while maintaining the system performance.

The approach is to develop detailed dynamic models that include dynamics up to 10's of KHz range in order to quantify interface stability specifications, and simplified models that can be used to aid in the conceptual system design and to help develop control strategies from system start-up all the way through normal, abnormal, and shut-down operations. The high fidelity model for the fuel cell involves the fuel cell voltage relation, the conservation equations, the ion diffusion, the charge transfer kinetics, as well as the inherent impedances. For the power system, the model involves modeling certain key power system components such as converters and inverters. Similar models need to be developed for the microturbine and other auxiliary components like diffusers, heat exchangers, heaters and humidifiers. The research in this area is continuing with the maturity in model development, model calibration with test data, and then embarking on controls design and performance studies.

Ref.: Kopasakis, G., et al., "A Theoretical Solid Oxide Fuel Cell Model for System Controls and Stability Analysis," to be presented at the ASME Turbo Expo, Barcelona, Spain, June 2006. 


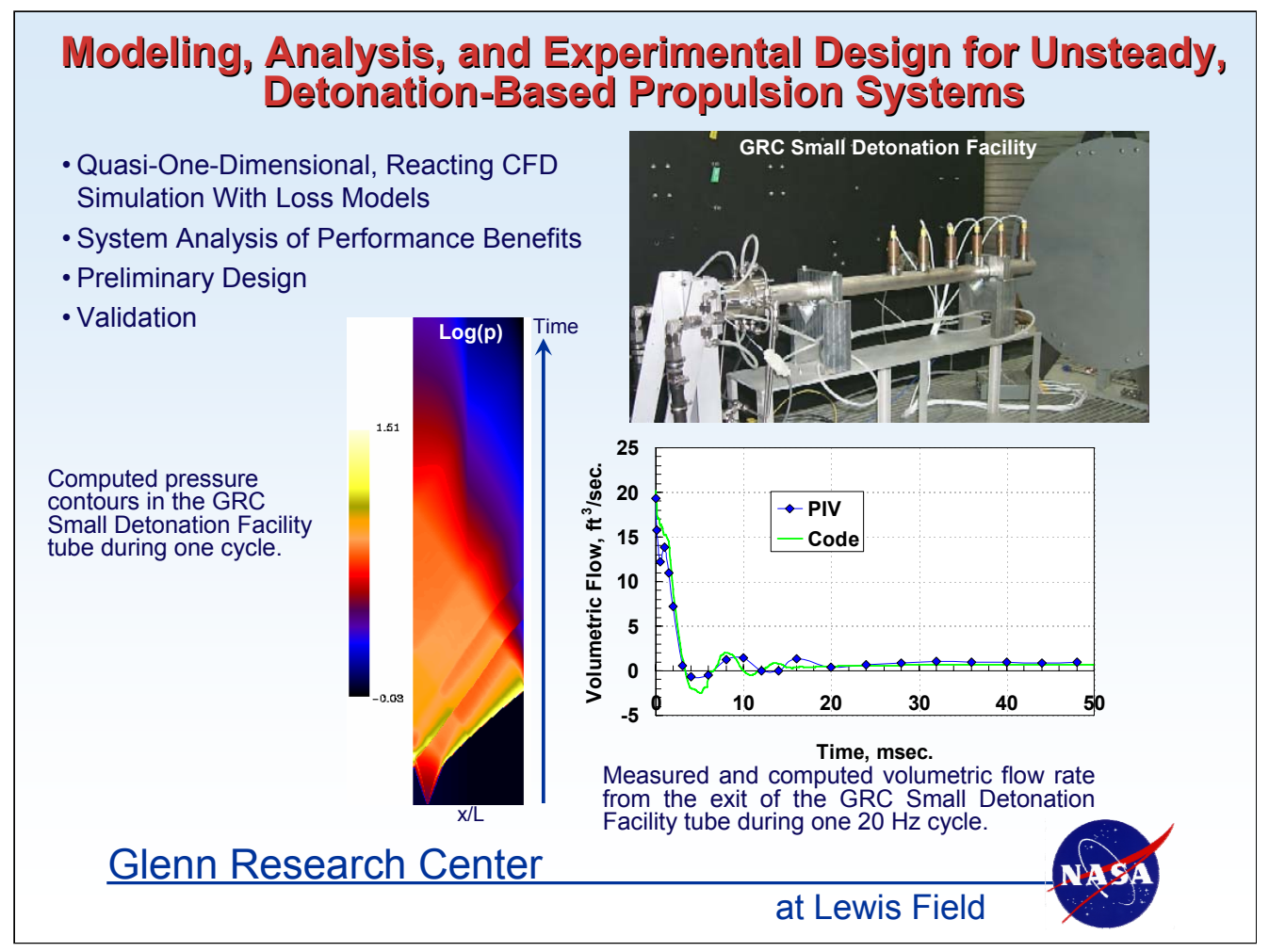

\section{Modeling, Analysis, and Experimental Design for Unsteady, Detonation-Based Propulsion Systems}

GRC has been investigating detonation-based propulsion systems and components for several years under the Constant Volume Combustion Cycle Engine (CVCCE) project. The Controls and Dynamics Branch is supporting this research primarily through modeling and analysis of various configurations and validating these models through experiments.

The Controls and Dynamics branch has pursued a relatively simple, quasi-one-dimensional modeling approach, which captures the essential physics of the detonative process while providing rapid turnaround of results on desktop level computing platforms. The resulting code has been used in the design of validation experiments, to assess potential heat and structural loads, and provide data for acoustic analyses. It has provided performance data for stand-alone applications and, combined with appropriate averaging techniques for the emitted and ingested flows has been used to assess performance as a pressure-gain component in a gas turbine based system.

The left image in this slide represents a sample computed flowfield from the code. It is presented in the form of pressure contours along the length of a purely one-dimensional tube, over the course of one cycle. The photograph in the upper right represents one of the various test articles designed and implemented for experimental validation. The testing included the first successful Digital Particle Imaging Velocimetry (DPIV) mapping of the exit flowfield from a detonative device. The figure in the lower right shows an excellent match between the predicted and actual volumetric flow rate near the device exit plane over the course of one cycle.

Ref: Paxson, D.E., "Performance Evaluation Method for Ideal Airbreathing Pulse Detonation Engines," AIAA Journal of Propulsion and Power, Vol. 20, No. 5, Sept. to Oct. 2004. 


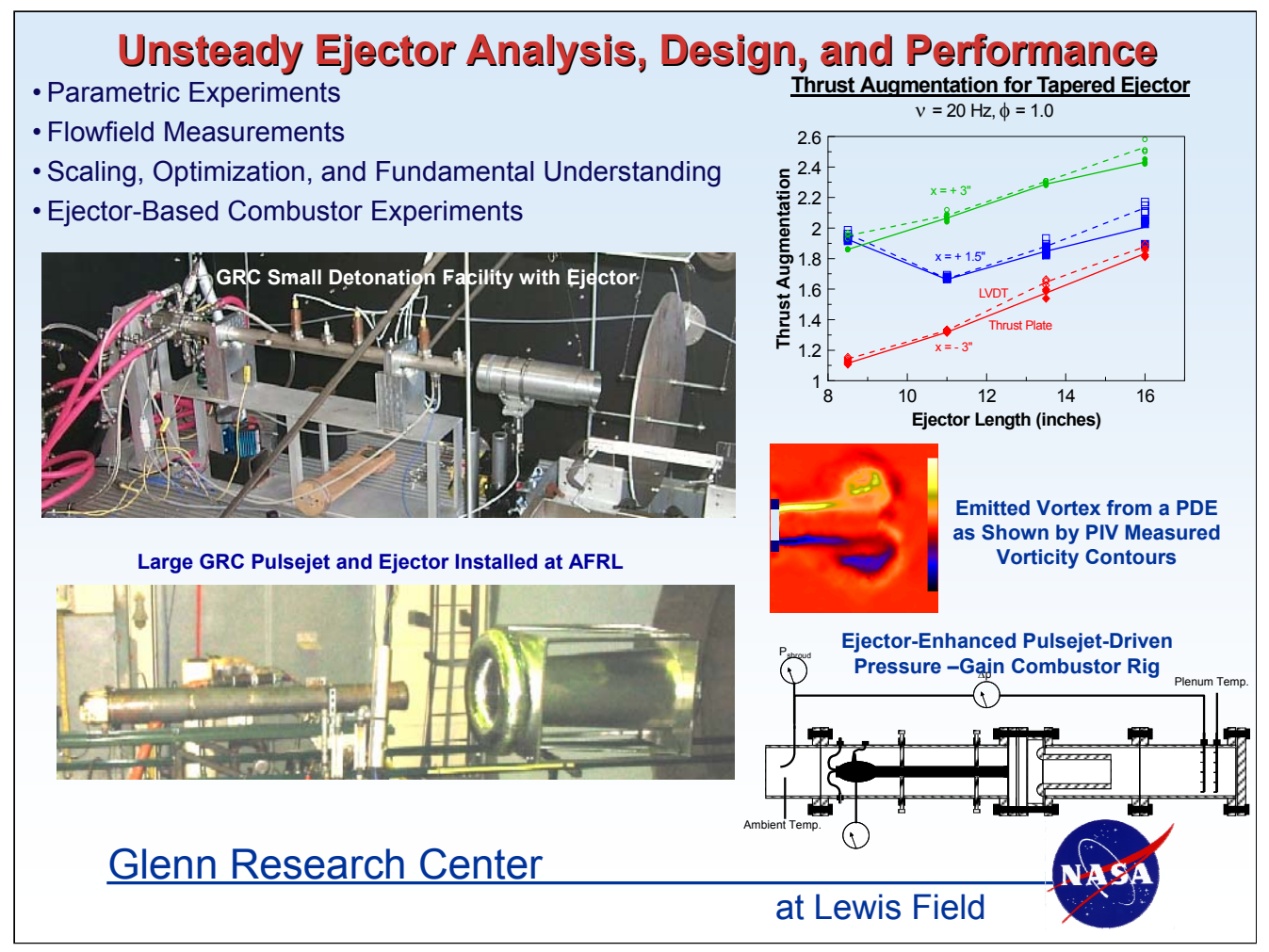

\section{Unsteady Ejector Analysis, Design, and Performance}

A natural component of the CVCCE (Constant Volume Combustion Cycle Engine) project is an investigation of unsteady ejector or thrust augmenting technology. This is so for two primary reasons. First, because unsteady ejectors have been purported to have vastly superior performance characteristics than their steady counterparts. Second, because the rapid mixing that is thought to occur in unsteady ejectors may be used to smooth and cool the flow emitted from a detonative combustor before it is presented to a downstream turbine in a pressure-gain, gas turbine concept.

The Controls and Dynamics Branch has been at the forefront of the research on trying to fundamentally understand the physics of unsteady ejector process, and validate some of the performance claims, using basic experiments. Analytical data using a simulation to predict thrust augmentation with ejectors has been correlated with experimental data with a variety of unsteady thrust sources, e.g., a Pulse Detonation Engine, two different sized pulsejets, a Hartmann tube, and a synthetic jet. These analytical and experimental investigations have led to the following accomplishments to date: i) Obtained thrust augmentation levels of 2.5, ii) Verified rapid mixing leading to relatively short ejectors, iii) Developed diameter scaling laws for optimal performance, iv) Identified the emitted vortex common to all pulsed flows as being critical to performance, v) Obtained a vortex characterizing parameter which can be used to predict peak augmentation performance, and vi) Demonstrated unsteadiness mitigation and pressure-gain in a combustor arrangement.

Ref: Paxson, D.E., “An Experimental Investigation of Unsteady Thrust Augmentation using a SpeakerDriven Jet," AIAA-2004-0092, 42nd Aerospace Sciences Meeting and Exhibit, Reno, NV, January 2004. 


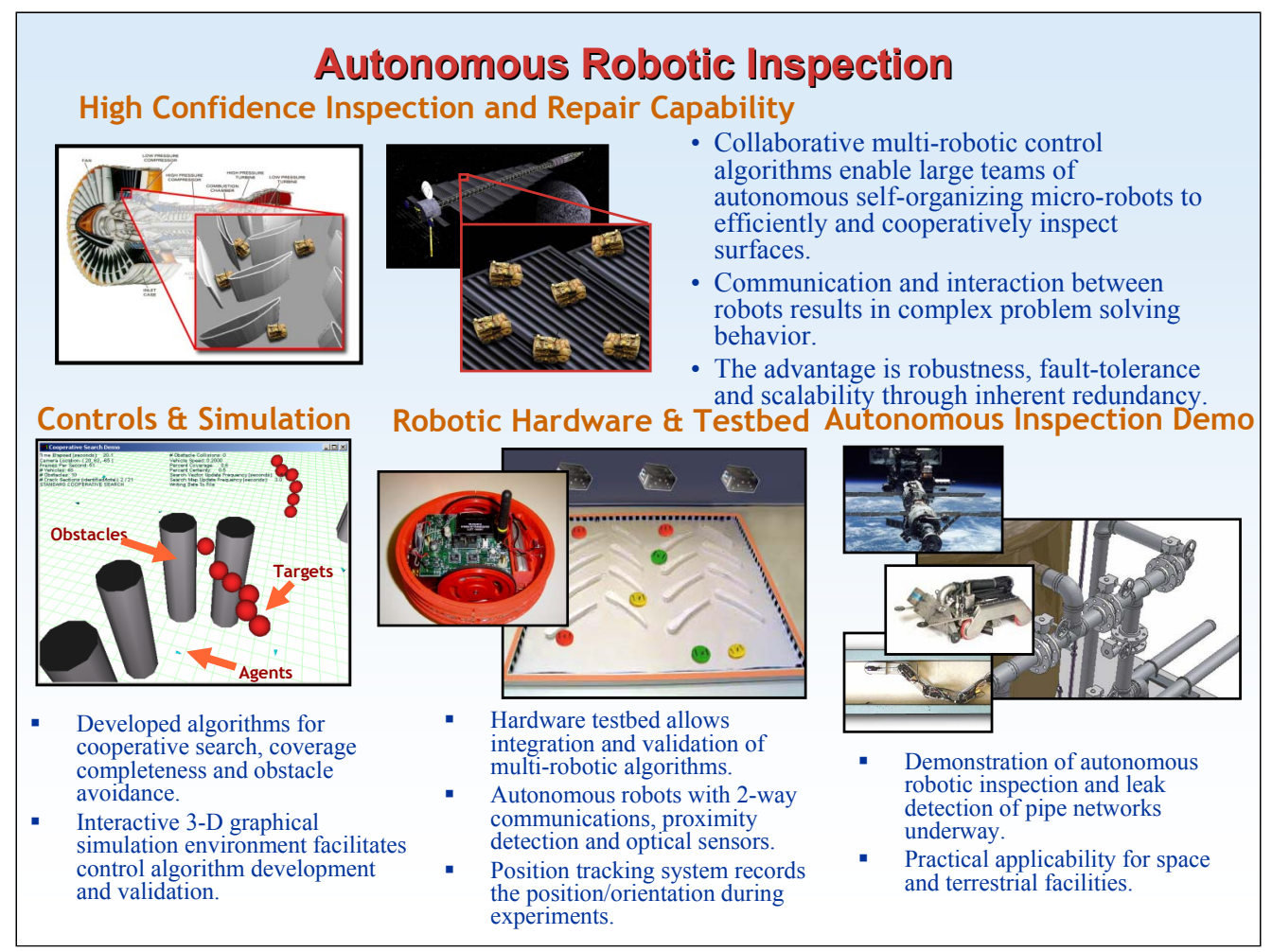

\section{Collaborative Robotic Controls for Autonomous Inspection}

NASA GRC is developing the collaborative multi-agent robotic control algorithms that will enable the autonomous inspection and repair of future space systems. High confidence inspections and repair will be performed autonomously by large groups of cooperative miniature robots that will deploy and explore the system surfaces in search of damage. The goal is to replace manual inspections that are tedious, expensive and time-consuming, and allow early detection of problems that could otherwise lead to catastrophic failures.

In a multi-robotic system, communication and interaction between the robots will result in self-organized, emergent group behavior that solves a given complex problem, such as cooperative inspection and repair. The advantages of robustness, fault-tolerance and scalability are realized through the inherent redundancy of the system. In addition, the relatively simple robotic controls demand minimal computational capability, which allows for greater miniaturization. Researchers under this effort have developed and tested a range of algorithms to address pertinent control objectives such as cooperative search, coverage completeness and obstacle avoidance. Algorithms range from those that require centralized coordination and communication to those that take a more distributed approach and rely only on indirect interactions.

To facilitate the design and testing of these algorithms, an interactive 3-D graphical simulation environment was developed. A robotic test-bed facility has been constructed that will allow integration and proof-of-concept demonstrations. Finally, a practical demonstration of autonomous robotic inspection and leak detection of pipe networks is currently under development.

Ref: Wong, E., and Litt, J. S., “Autonomous Multi-Agent Robotics for Inspection and Repair of Propulsion Systems," AIAA 1st Intelligent Systems Technical Conference, Chicago, IL, September 2004. 


\section{Conclusion}

- Controls and health management technologies play a critical role in making "Intelligent Propulsion Systems" a reality.

- It is essential that the controls and diagnostics expertise be integrated early into the system concept development to enable system intelligence in the design.

- A multidisciplinary cross-organizational collaborative approach is essential for successful development and demonstration of Intelligent System technologies.

- Critical technologies to be developed for controls and health management of propulsion systems include:

- improved understanding and modeling of the dynamic behavior to be controlled or monitored.

- robust and adaptive control and diagnostics algorithms.

- appropriate sensors and actuators to aid in development and implementation of the overall control system.

- A system level approach is essential to ensure that various components of a control or diagnostic system work together as an integrated system to achieve the desired objectives.

\section{Glenn Research Center}

at Lewis Field

\section{Conclusion}

In conclusion, the above figure lists the major challenges currently being faced by the propulsion control design engineers. The Controls and Dynamics Branch at NASA GRC is working in strong partnership with industry, academia and other government agencies to develop the propulsion control and health management technologies that will help make the vision of "Intelligent Propulsion Systems" a reality to enable NASA's Space Exploration and Aeronautics Research Mission objectives. Our aim is to use the public resources in a most efficient manner to make a significant contribution to the aggressive goals that have been set by the administrator in the latest strategic plan for NASA, and to ensure that our activities are aligned with the goals of the NASA Themes that we participate in. 
Public reporting burden for this collection of information is estimated to average 1 hour per response, including the time for reviewing instructions, searching existing data sources, gathering and maintaining the data needed, and completing and reviewing the collection of information. Send comments regarding this burden estimate or any other aspect of this collection of information, including suggestions for reducing this burden, to Washington Headquarters Services, Directorate for Information Operations and Reports, 1215 Jefferson Davis Highway, Suite 1204, Arlington, VA 22202-4302, and to the Office of Management and Budget, Paperwork Reduction Project (0704-0188), Washington, DC 20503.

\begin{tabular}{|l|l|l|}
\hline 1. AGENCY USE ONLY (Leave blank) & $\begin{array}{c}\text { 2. REPORT DATE } \\
\text { December } 2005\end{array}$ & $\begin{array}{r}\text { 3. REPORT TYPE AND DATES COVERED } \\
\text { Technical Memorandum }\end{array}$ \\
\hline
\end{tabular}

\section{TITLE AND SUBTITLE}

5. FUNDING NUMBERS

NASA Glenn Research in Controls and Diagnostics for Intelligent Aerospace Propulsion Systems

6. AUTHOR(S)

Sanjay Garg

WBS 561581.02.01.03.03

National Aeronautics and Space Administration

John H. Glenn Research Center at Lewis Field

Cleveland, Ohio 44135-3191

8. PERFORMING ORGANIZATION

REPORT NUMBER

E-15393

9. SPONSORING/MONITORING AGENCY NAME(S) AND ADDRESS(ES)

10. SPONSORING/MONITORING

AGENCY REPORT NUMBER

National Aeronautics and Space Administration

Washington, DC 20546-0001

NASA TM-2005-214036

\section{SUPPLEMENTARY NOTES}

Prepared for the 17th International Symposium on Airbreathing Engines (ISABE) cosponsored by the German National Organizing Committee, DGLR, and MTU Aero Engines GmbH, Munich, Germany, September 4-9, 2005. Responsible person, Sanjay Garg, organization code RIC, 216-433-2685.

12a. DISTRIBUTION/AVAILABILITY STATEMENT

12b. DISTRIBUTION CODE

Unclassified - Unlimited

Subject Category: 07

Available electronically at http://gltrs.grc.nasa.gov

This publication is available from the NASA Center for AeroSpace Information, 301-621-0390.

13. ABSTRACT (Maximum 200 words)

With the increased emphasis on aircraft safety, enhanced performance and affordability, and the need to reduce the environmental impact of aircraft, there are many new challenges being faced by the designers of aircraft propulsion systems. Also the propulsion systems required to enable the NASA (National Aeronautics and Space Administration) Vision for Space Exploration in an affordable manner will need to have high reliability, safety and autonomous operation capability. The Controls and Dynamics Branch at NASA Glenn Research Center (GRC) in Cleveland, Ohio, is leading and participating in various projects in partnership with other organizations within GRC and across NASA, the U.S. aerospace industry, and academia to develop advanced controls and health management technologies that will help meet these challenges through the concept of Intelligent Propulsion Systems. The key enabling technologies for an Intelligent Propulsion System are the increased efficiencies of components through active control, advanced diagnostics and prognostics integrated with intelligent engine control to enhance operational reliability and component life, and distributed control with smart sensors and actuators in an adaptive fault tolerant architecture. This paper describes the current activities of the Controls and Dynamics Branch in the areas of active component control and propulsion system intelligent control, and presents some recent analytical and experimental results in these areas.

14. SUBJECT TERMS

Propulsion; Engine control; Control systems design; Adaptive control

\begin{tabular}{|c|c|}
\hline $\begin{array}{c}\text { 17. SECURITY CLASSIFICATION } \\
\text { OF REPORT } \\
\text { Unclassified }\end{array}$ & $\begin{array}{c}\text { 18. SECURITY CLASSIFICATION } \\
\text { OF THIS PAGE } \\
\text { Unclassified }\end{array}$ \\
\hline
\end{tabular}

NSN 7540-01-280-5500

19. SECURITY CLASSIFICATION
OF ABSTRACT
Unclassified

Standard Form 298 (Rev. 2-89)

Prescribed by ANSI Std. Z39-18 298-102 

